\title{
Comparações entre procedimentos laboratoriais das técnicas de produção de gases e incorporação de radiofósforo pelos microrganismos na avaliação in vitro de alimentos para ruminantes
}

\author{
SARITA PRISCILA GobBo \\ Bióloga
}

Orientador: PROF. DR. AdIBE LUIZ ABDALLA

Dissertação apresentada ao Centro de Energia Nuclear na Agricultura, Universidade de São Paulo, para obtenção do título de Mestre em Ciências, Área de Concentração: Energia Nuclear na Agricultura

PIRACICABA

Estado de São Paulo - Brasil

Outubro - 2001 


\section{DEDICO:}

aos meus pais Nivaldo e Hermínia, pelo esforço na minha formação e, ao Bruno por estar sempre ao meu lado. 


\section{AGRADEÇO:}

Ao Prof. Dr. Adibe Luiz Abdalla pela confiança, orientação e ajuda na execução do trabalho;

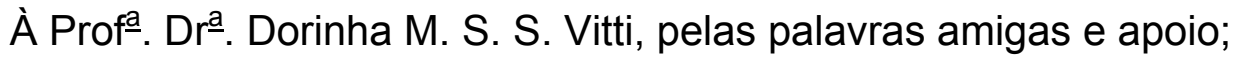

a Ives Cláudio da Silva Bueno pela incansável ajuda e paciência, pois só os verdadeiros amigos o conseguem fazer;

aos amigos Mariana C. Machado, Cibele Longo, Eduardo F. Nozella, Raquel S. Dias e Liliana Oetting, pelo estímulo e ajuda;

a Sérgio Lúcio Salomon Cabral Filho, pela constante alegria e auxílio nos momentos mais difíceis;

a Maria Regina S. R. Peçanha e Lécio A. Castilho, por sua colaboração, organização e competência no auxílio das análises;

aos estagiários do Laboratório de Nutrição Animal, em especial a Patrícia B. de Godoy, Carina Pavan, Daniela de Paula Silveira, Ana Paola Negri, Wagner A. Andia e José Antônio $C$. de Castro, pela ajuda na execução das análises e principalmente, pela amizade;

ao Centro de Energia Nuclear na Agricultura, pela oportunidade da realização dos meus estudos;

à FAPESP, por financiar os estudos através do apoio financeiro concedido e;

a Deus, por estar sempre presente em minha vida. 


\section{SUMÁRIO}

Página

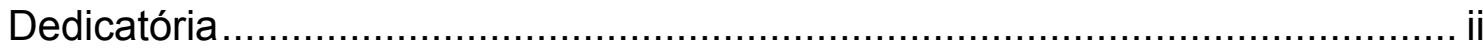

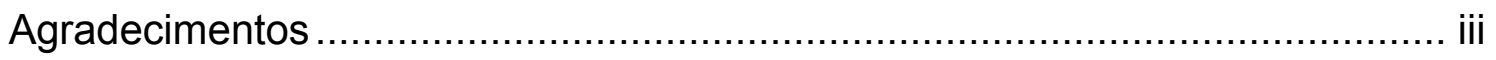

Lista de figuras..................................................................................... vii

Lista de tabelas .....................................................................................

Lista de siglas, abreviaturas e símbolos ……......................................... ix

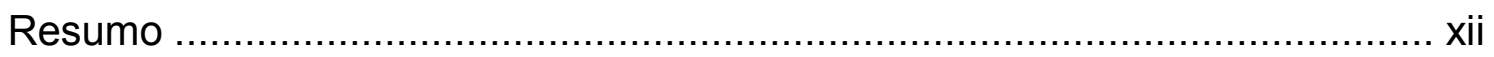

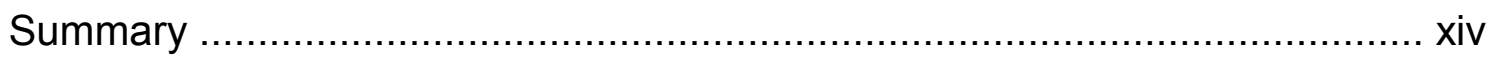

1. INTRODUÇÃO

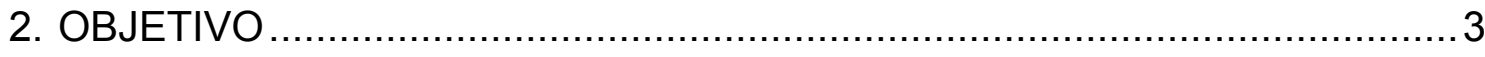

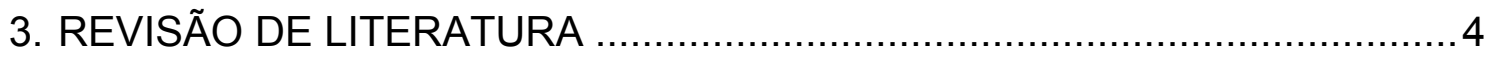

3.1. Incorporação in vitro de ${ }^{32} \mathrm{P}$ para avaliação de síntese microbiana........4

3.2. Produção de gases in vitro ....................................................... 6

3.3. Degradabilidade ruminal in situ ...................................................

3.4. Digestibilidade in vitro (Tilley \& Terry) ............................................ 8

3.5. Estimativa de nutrientes digestíveis totais ......................................... 9

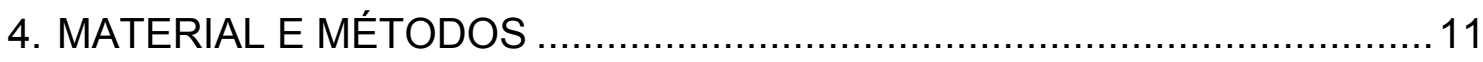

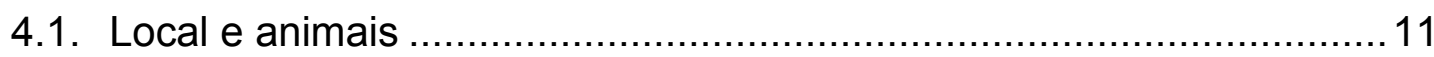

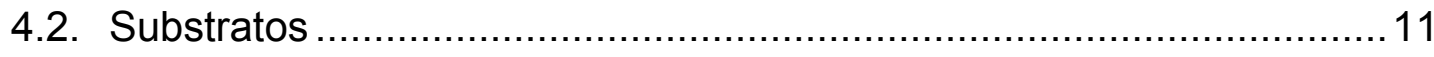

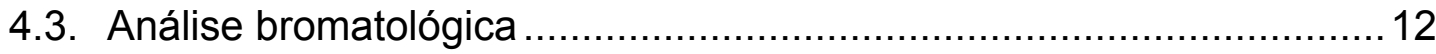

4.4. Síntese microbiana através da incorporação de radiofósforo ..............12 
Página

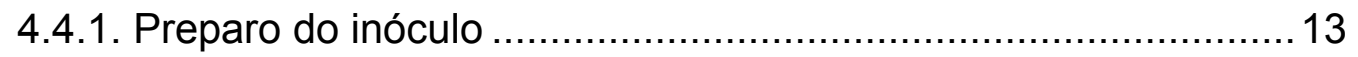

4.4.2. Separação da massa microbiana ............................................. 14

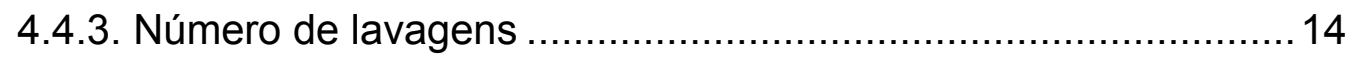

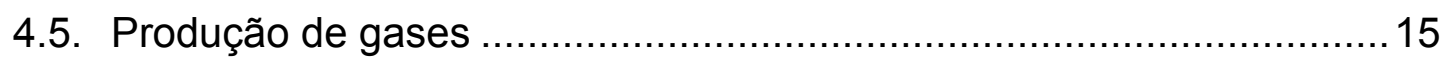

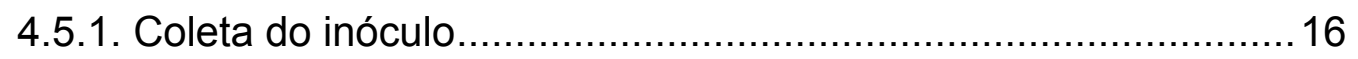

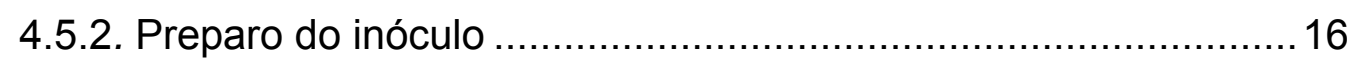

4.6. Degradabilidade in vitro da matéria seca .......................................... 16

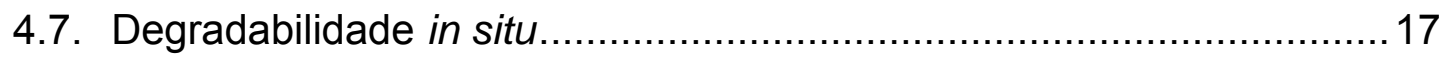

4.8. Digestibilidade in vitro (Tilley \& Terry) ............................................ 18

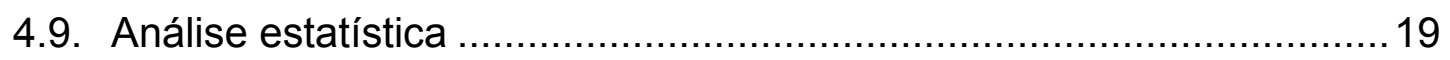

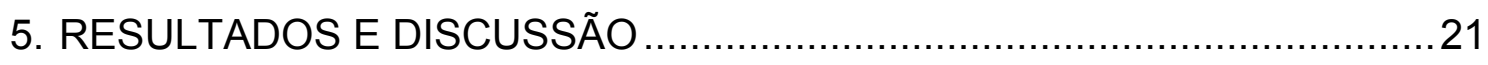

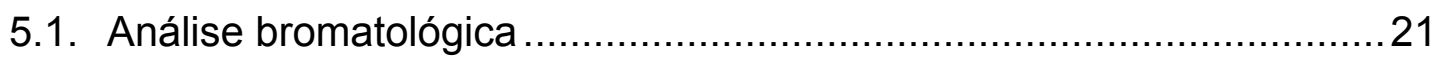

5.2. Síntese microbiana através da incorporação de radiofósforo ..............22

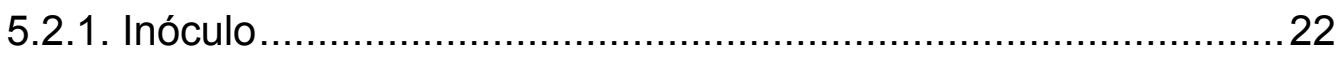

5.2.2. Separação da massa microbiana .............................................23

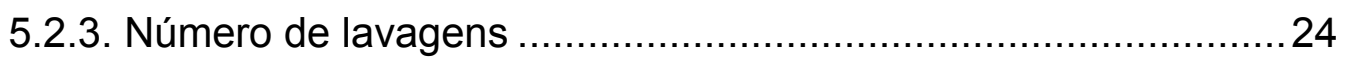

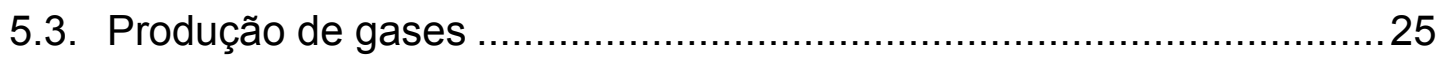

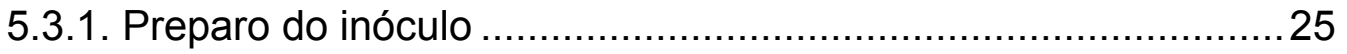

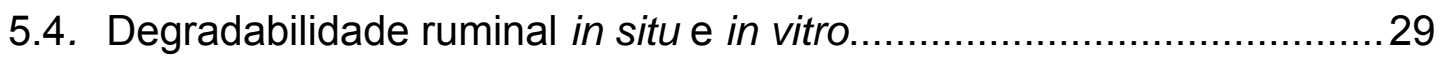

5.5. Digestibilidade in vitro (Tilley \& Terry) ….......................................... 32

5.6. Correlações entre as metodologias testadas ...................................... 32

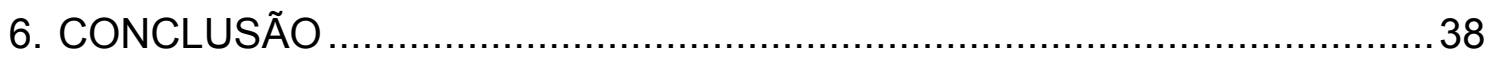


Página

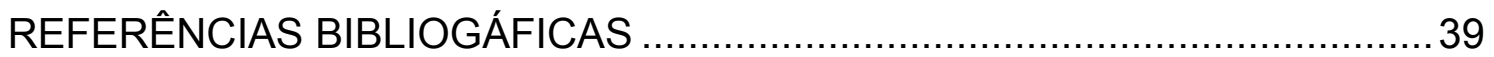




\section{LISTA DE FIGURAS}

Página

1. Diferenças na determinação de incorporação de $N$ pelos microrganismos ruminais, comparando diferentes proporções de inóculos.

2. Diferenças na determinação de incorporação de $N$ pelos microrganismos ruminais, usando-se rotação de 10000 e 18000rpm para separação da massa microbiana.

3. Cinética da produção de gases usando líquido ruminal como fonte de inóculo, com quatro concentrações diferentes de fase sólida ( $A=0 \%, B=25 \%, C=33 \%$ e $D=50 \%$ ).

4. Cinética de degradação ruminal in vitro $(\bullet)$ e in situ $(\mathbf{\Lambda})$ dos alimentos testados

5. Correlações entre as técnicas de degradabilidade in situ da MS e nutrientes digestíveis totais (NDT \%).

6. Correlações entre as metodologias de produção total de gases 48 e 96 horas com nitrogênio incorporado (mgN/gMS)

7. Correlações entre teores $\left(\mathrm{g} \cdot \mathrm{kg}^{-1}\right)$ em relação a degradabilidade efetiva (\%) (a), degradabilidade potencial in situ (\%) (b) e, digestibilidade in vitro $(\%)(c)$

8. Comparação entre as degradabilidades da matéria seca (MS) determinadas por técnicas in vitro e in situ.

9. Correlações entre as técnicas in situ e in vitro da MS, determinadas pela técnica de Tilley \& Terry modificada. 


\section{LISTA DE TABELAS}

Página

1. Análise de variância para cada um dos ensaios deste experimento

2. Resultados da análise bromatológica para os diferentes substratos utilizados

3. Eficiência de descontaminação (em \%) de radiofósforo extracelular usando 3 ou 4 lavagens, em relação ao uso de duas lavagens 25

4. Lag time dos seis substratos testados para cada inóculo. 26

5. Médias das variáveis de produção de gases in vitro incluindo quantias de fase sólida de líquido ruminal

6. Estimativa da degradabilidade ruminal in situ dos alimentos testados

7. Estimativa da degradabilidade ruminal in vitro dos alimentos testados 30

8. Resultados da digestibilidade in vitro da matéria seca 


\section{LISTA DE SIGLAS, ABREVIATURAS E SÍMBOLOS}

$(A+B) \quad$ degradabilidade ruminal potencial

$(a+b)$ taxa de degradação

A "washing loss", parâmetro do modelo proposto por Ørskov \& Mcdonald (1979), que determina a fração do substrato prontamente solúvel em água

a constante do modelo exponencial proposto por Ørskov \& Mcdonald (1979)

$A E_{e} \quad$ atividade específica extracelular

b constante do modelo exponencial proposto por Ørskov \& Mcdonald (1979)

B fração fermentável e insolúvel

c constante do modelo exponencial proposto por Ørskov \& Mcdonald (1979)

c taxa de degradação do substrato, em $\% / h^{-1}$

$\mathrm{CO}_{2} \quad$ dióxido de carbono

DE2\% degradabilidade ruminal a uma taxa de pasagem de $2 \% / \mathrm{h}^{-1}$

$D E G \quad$ degradabilidade da matéria seca in vitro

DIVMS digestibilidade in vitro da matéria seca

$d p m / m g$ desintegração por minuto em miligrama

$d p m_{e} \quad$ desintegrações extracelulares por minuto

$d p m_{i} \quad$ desintegrações intracelulares por minuto 


\begin{tabular}{|c|c|}
\hline$E E$ & extrato etéreo \\
\hline ENN & extrativo não nitrogenado \\
\hline epd & erro padrão da diferença das médias \\
\hline$F B$ & fibra bruta \\
\hline FDA & fibra em detergente ácido \\
\hline$F D N$ & fibra em detergente neutro \\
\hline$g$ & gramas ou força gravitacinal \\
\hline$g / k g M S$ & grama por quilograma de matéria seca \\
\hline G48 & volume de gás produzido em $48 \mathrm{~h}$ \\
\hline G96 & volume de gás produzido em $96 \mathrm{~h}$ \\
\hline$h$ & horas \\
\hline $\mathrm{H}_{2} \mathrm{SO}_{4}$ & ácido sulfúrico \\
\hline$k g$ & quilograma \\
\hline lag time & tempo de colonição \\
\hline$L A G$ & "lag time" \\
\hline$m g$ & miligrama \\
\hline$m l$ & mililitro \\
\hline MM & matéria mineral \\
\hline$m m$ & milímetro \\
\hline MS & matéria seca \\
\hline$N$ & nitrogênio ou normalidade \\
\hline$N: P$ & relação entre nitrogênio e fósforo na massa microbiana \\
\hline$N D T$ & estimativa de nutrientes digestíveis totais \\
\hline
\end{tabular}




$\begin{array}{ll}N_{i} & \text { nitrogênio incorporado à massa microbiana } \\ { }^{15} \mathrm{C} & \text { isótopo estável do nitrogênio } \\ { }^{\circ} \mathrm{r} & \text { grau Celsius } \\ { }^{32} P & \text { degradação da matéria seca no tempo (t) } \\ P & \text { radiofósforo } \\ P B & \text { prósforo ou probabilidade } \\ P_{e} & \text { fósforo extracelular } \\ P_{i} & \text { fósforo incorporado à massa microbiana } \\ P O T & \text { potencial de produção de gases } \\ r & \text { coeficiente de correlação de Pearson } \\ R E L 1 & \text { razão entre G48 e G96h } \\ R E L 2 & \text { razão entre G96h e POT } \\ r p m & \text { rotações por minuto } \\ t & \text { tempo } \\ \mu C i & \text { micro Curie } \\ \mu l & \text { microlitro }\end{array}$




\title{
Comparações entre procedimentos laboratoriais das técnicas de produção de gases e incorporação de radiofósforo pelos microrganismos na avaliação in vitro de alimentos para ruminantes
}

\author{
Autora: Sarita Priscila Gobbo \\ Orientador: Prof. Dr. Adibe Luiz Abdalla
}

\section{RESUMO}

Este trabalho foi desenvolvido com a finalidade de testar alterações nas metodologias in vitro de produção de gases (diferentes proporções de inóculo) e incorporação de ${ }^{32} \mathrm{P}$ (velocidade de centrifugação, número de lavagens e diferentes tipos de inóculos) para adequá-las às condições climáticas e às especificidades da microbiota dos ruminantes mantidos no clima tropical brasileiro. Além dessas técnicas utilizadas, foram feitas determinações de análise bromatológica com posterior análise de nutrientes digestíveis totais, degradabilidade ruminal in situ e digestibilidade in vitro a partir da técnica dos dois estágios.

Os substratos testados foram divididos em, fibrosos (feno de alfafa e capim colonião), concentrados (milho grão e farelo de soja) e fermentado (silagem de milho). $O$ delineamento experimental utilizado foi inteiramente casualizado, todos os substratos foram avaliados para cada uma das variáveis com pelo menos três repetições no tempo. Cada variável foi comparada por análise de variância considerando a hipótese de nulidade dentro dos substratos. As correlações entre as metodologias foram testadas quando biologicamente significantes e compatíveis. 
A técnica de incorporação in vitro de ${ }^{32} \mathrm{P}$, obteve resultados satisfatórios $(P<0,05)$ em relação à velocidade de centrifugação e número de lavagens. Os diferentes tipos de inóculos testados (100\% fase líquida do rúmen, $50 \%$ fase líquida e $50 \%$ fase sólida) não apresentaram diferença significativa $(P>0,05)$.

As diferentes proporções do inóculo testado na técnica in vitro de produção de gases (A contendo $100 \%$ de fase líquida e $0 \%$ de fase sólida; inóculo $B, 75 \%$ de fase líquida e $25 \%$ de fase sólida; inóculo C, $67 \%$ de fase líquida e $33 \%$ de fase sólida; inóculo D, $50 \%$ de fase líquida e $50 \%$ de fase sólida) apresentaram diferença significativa $(P<0,01)$; os fatores analisados permitiram a interpretação de que usando o inóculo com maior porcentagem de fase sólida, o processo fermentativo foi mais parecido ao potencial de produção de gases.

Para a técnica in vitro de incorporação de ${ }^{32} \mathrm{P}$ sugere-se usar uma velocidade de centrifugação de 39.907g, 4 lavagens e um inóculo com apenas a fase líquida do conteúdo ruminal. É sugerido que para a técnica in vitro de produção de gases pode ser usado um inóculo contendo $50 \%$ de fase sólida e $50 \%$ de fase líquida do conteúdo ruminal. 


\title{
Comparisons between laboratorial procedures of gas production technique and radiophosphorous microbial incorporation in in vitro ruminant feed evaluation
}

\author{
Author: Sarita Priscila Gobbo \\ Adviser: Prof. Dr. Adibe Luiz Abdalla
}

\section{SUMMARY}

This study was developed to test the adaptations in in vitro methodologies of gas production (different proportion of solid phase in the inoculum) and ${ }^{32} \mathrm{P}$ incorporation technique (centrifugation speed, number of washings and different kinds of inoculum) to adequate them to the climate condition and to the microbiota specifications of the ruminants kept in the Brazilian tropical climate. Besides these techniques, bromatological analysis determinations were made with further total digestible nutrients and also, in situ rumen degradability and in vitro digestibility from the two-stage technique.

The tested substrata were divided in fibrous (Panicum grass and Lucerne hay), concentrated (soybean meal and corn grain) and fermented (corn silage). The experimental design was completely randomized, where all the substrata were evaluated for each of the variables with at least three repetitions. Each variable was compared for analysis of variance considering the hypothesis, within substrata. The correlations between methodologies were tested when biologically significant and compatible.

The ${ }^{32} \mathrm{P}$ in vitro incorporation technique obtained satisfactory results $(P<0,05)$ in relation to the centrifugation speed and the number of washings. 
The two different kinds of tested inocula (100\% rumen liquid phase, and $50 \%$ both liquid and solid phase) showed no significant difference $(P>0,05)$.

The different inoculum proportion tested for in vitro gas production (inoculum A containing $100 \%$ liquid phase and $0 \%$ solid phase; inoculum $B, 75 \%$ liquid phase and $25 \%$ solid phase; inoculum C, $67 \%$ liquid phase and $33 \%$ solid phase; and inoculum D, 50\% both liquid and solid phases) showed significant difference; the analyzed factors allowed the interpretation that using the inoculum with higher solid phase percentage, the fermentation process was more similar to the gas production potential.

In the in vitro ${ }^{32} \mathrm{P}$ incorporation technique it is suggested to use a centrifugation speed of $39,907 \mathrm{~g}, 4$ washings and an inoculum with only liquid phase from the rumen. It is suggested that for the in vitro gas production technique can be used an inoculum containing $50 \%$ of solid phase and $50 \%$ of liquid phase. 


\section{Errata}

Substituir Tabela 1 referente à página 19, pela Tabela a seguir.

Tabela 1. Esquema de análise de variância para cada um dos ensaios deste experimento

\begin{tabular}{lcccc}
\hline \multirow{2}{*}{ fontes de variação } & \multicolumn{4}{c}{ graus de liberdade } \\
\cline { 2 - 5 } & ensaio 1 & ensaio 2 & ensaio 3 & ensaio 4 \\
\hline substratos & 4 & 4 & 4 & 4 \\
repetições & 2 & 2 & 2 & 2 \\
tratamentos & 3 & 1 & 1 & 2 \\
tratamentos X substratos & 12 & 4 & 4 & 8 \\
erro & 38 & 18 & 18 & 28 \\
\hline total & 59 & 29 & 29 & 44 \\
\hline
\end{tabular}

Substituir Tabela 2 referente à página 22, pela Tabela a seguir.

Tabela 2. Resultados da análise bromatológica ${ }^{1}$ para os diferentes substratos utilizados.

\begin{tabular}{lccccccc}
\hline substratos & $M S$ & $E E$ & $F B$ & $F D N$ & $F D A$ & $P B$ & $N D T^{2}$ \\
\hline milho grão & 93,8 & 69,4 & 6,2 & 26,7 & 4,4 & 9,3 & 81,5 \\
silagem de milho & 27,8 & 35,3 & 26,8 & 56,8 & 30,8 & 7,3 & 64,0 \\
feno de alfafa & 43,3 & 35,2 & 31,4 & 50,3 & 32,9 & 18,7 & 60,0 \\
capim colonião & $\mathrm{nd}^{3}$ & 27,6 & 46,2 & 72,6 & 48,6 & 4,3 & 50,8 \\
farelo de soja & 88,2 & 28,2 & 11,3 & 15,8 & 10,6 & 45,9 & 94,7 \\
\hline e.p.m & 2,28 & 1,00 & 18,92 & 7,36 & 3,50 & 2,09 & 11,05 \\
\hline
\end{tabular}

${ }^{1} \mathrm{MS}$ expressa em \% de matéria verde e os demais valores expressos em $\mathrm{g} / \mathrm{kg}$ de MS.

${ }^{2}$ NDT: estimativa de nutrientes digestíveis totais (\%)

${ }^{3}$ nd: valor não determinado

${ }^{4}$ epm: erro padrão entre as médias 


\section{INTRODUÇÃO}

Atualmente, existem diversas técnicas laboratoriais para avaliação de alimentos destinados a ruminantes, utilizadas principalmente para estimar o seu valor nutritivo. Dentre essas, destacamos as técnicas in vitro de produção de gases e de incorporação de radiofósforo $\left({ }^{32} \mathrm{P}\right)$ pelos microrganismos do rúmen. Essas técnicas são simples, de baixo custo e possuem certa confiabilidade, sendo de grande importância para a nutrição animal.

O uso de radioisótopos em técnicas de incorporação in vitro tem demonstrado resultados satisfatórios em pesquisas relacionadas aos microrganismos do rúmen. Medidas da capacidade de fermentação para estimar o crescimento microbiano nessa técnica são procedimentos úteis, permitindo que a atividade microbiana seja avaliada. Porém, é necessário que sejam feitas adaptações para adequá-las às condições dos tipos de alimentos de clima tropical, pois essas metodologias foram desenvolvidas em países de clima temperado, testando os alimentos característicos da região.

A técnica in vitro de produção de gases é reconhecida como uma das melhores para descrever a cinética fermentativa dos alimentos. A produção de gases é diretamente proporcional à fermentação microbiana do alimento e, como pode ser medida a intervalos freqüentes, permite analisar o modo como ocorre o ataque microbiano na degradação do alimento no rúmen.

Esse sistema possibilita correlacionar a produção microbiana com a matéria orgânica fermentada. É possível em um único experimento analisar diversos alimentos e, através dos resultados, demonstrar sua degradabilidade 
potencial, além de fornecer medidas dos produtos de fermentação (gases), obtendo uma melhor interpretação desse processo. A principal fonte de erros da técnica in vitro de produção de gases está no uso do inóculo, devido a diferença existente na população microbiana das fases sólidas e líquidas do rúmen. 


\section{OBJETIVO}

O presente trabalho foi desenvolvido com a finalidade de testar alterações nas metodologias in vitro de incorporação de radiofósforo (velocidade de centrifugação, número de lavagens e tipo de inóculo) e produção de gases (diferentes tipos de inóculo), para adequá-las às condições climáticas e às especificidades da microbiota dos ruminantes mantidos no clima tropical brasileiro. 


\section{REVISÃO DE LITERATURA}

\subsection{Incorporação in vitro de ${ }^{32} \mathrm{P}$ para avaliação de síntese microbiana}

O conhecimento do potencial de produção de massa microbiana a partir do alimento é de elevada importância, pois as exigências de proteínas para produção ou mantença dos ruminantes, são supridas pela síntese microbiana a partir da degradação dos alimentos no rúmen, da reciclagem de nitrogênio endógeno via saliva, da reciclagem do nitrogênio microbiano e da proteína dietética não degradada no rúmen (Boer \& Murphy,1987).

A quantificação da proteína microbiana sintetizada no rúmen como resultado da fermentação microbiana é de interessante pois exibe o crescimento da população microbiana e a formação da biomassa, mostrando a influência da dieta neste crescimento (Dove \& Milne, 1994).

A utilização de ${ }^{32} \mathrm{P}$ para a determinação da síntese microbiana tem mostrado ser bastante eficiente. Através da incubação in vitro de uma determinada quantidade de material em meio contendo saliva artificial, líquido do rúmen como fonte de inóculo e uma pequena quantidade de radiofósforo em solução, pode-se medir a taxa de incorporação do ${ }^{32} \mathrm{P}$, avaliando assim a atividade microbiana. O método baseia-se na relação entre a incorporação do fósforo na matéria microbiana e a síntese da proteína, utilização da amônia ou produção de ácidos graxos voláteis, em períodos de incubação curtos, usando

${ }^{32} \mathrm{P}$ como marcador (Van Nevel \& Demeyer, 1977; Vitti et al., 1988). 
A metodologia para o cálculo do crescimento microbiano a partir da incorporação de radiofósforo descrita por Van Nevel \& Demeyer (1977), descreve que a atividade específica do ${ }^{32} \mathrm{P}$ extracelular $\left(A E_{e}\right)$, em $\mathrm{dpm} / \mathrm{mg}$, é dada pela relação entre a contagem da atividade da porção sobrenadante $\left(d p m_{e}\right)$, ou extracelular e o teor de fósforo $(\mathrm{P})$ total extracelular $\left(P_{e}\right)$ na amostra encaminhada para contagem, em mg, ou seja:

$$
A E_{e}=d p m_{e} / P_{e}
$$

A quantidade de $\mathrm{P}$ incorporado à massa microbiana $\left(P_{i}\right)$, em $\mathrm{mg}$, é dada pela relação entre as contagens da atividade no material precipitado $\left(d p m_{i}\right)$, ou intracelular, e a atividade específica extracelular $\left(A E_{e}\right)$ :

$$
P_{i}=d p m_{i} / A E_{e}
$$

Estes autores determinaram ainda a relação entre $\mathrm{N}$ e $\mathrm{P}$ incorporado à massa microbiana como sendo um valor praticamente fixo, valendo $8,37 \pm$ 0,75 , o que permite a estimativa da quantidade de nitrogênio incorporado $\left(N_{i}\right)$ através da equação:

$$
N_{i}=P_{i} .8,37
$$

Discutindo sobre o tempo de incubação, Van Nevel \& Demeyer (1977) ressaltaram a importância de se usar o menor tempo possível para detecção do crescimento microbiano, sem que haja interferência da reciclagem dos microrganismos, sendo aumentada à medida que o substrato é degradado. Isto é bastante coerente levando em consideração o tipo de substrato por eles testados, predominantemente alimentos originários de regiões de clima temperado que possuem tempo de colonização (lag time) curto. Neste mesmo trabalho, sugerem como tempo de incubação um período de 4 horas e a utilização de 5 lavagens para descontaminação das amostras.

Vitti \& Silva Filho (1985), testando períodos de incubação (2, 4 e 6 horas) e número de lavagens (2 e 3 ), observaram que existe diferença significativa $(P<0,01)$ em relação aos tempos de incubação e número de 
lavagens. Os resultados que obtiveram maiores coeficientes de variação foram para 2 e 4 horas e 3 lavagens.

Trabalhando com gramíneas tropicais, Bueno (1998) mostra que por apresentarem um teor de fibra mais elevado e uma conseqüente menor fração de substâncias prontamente fermentáveis, apresentam um lag time maior, aproximadamente de 8 a 12 horas. $O$ autor sugere que o tempo de incubação para à técnica in vitro de síntese microbiana deveria ser acrescido para pelo menos o mesmo tempo do lag time.

Para Van Nevel \& Demeyer (1977) a contribuição dos substratos provenientes do próprio inóculo é nula, uma vez que os animais ficaram em jejum por um período de 24 horas. Hoje sabe-se que, mesmo em períodos prolongados de jejum, resquícios de nutrientes provêm da dieta ou da reciclagem microbiana. Bueno (1998) propôs a inclusão de um branco para descontar o crescimento microbiano proveniente de outra fonte de nutrientes que não a dos alimentos a serem testados.

\subsection{Produção de gases in vitro}

A produção de gases é diretamente proporcional à fermentação microbiana do alimento, e como pode ser medida a intervalos freqüentes, permite avaliar o modo como ocorre o ataque microbiano na degradação do alimento no rúmen.

Este sistema possibilita correlacionar a produção microbiana com a matéria orgânica fermentada. Para conversão da produção de gases em matéria orgânica digerida são necessárias equações de regressão. Um dos modelos matemáticos que melhor descreve a produção de gases in vitro foi proposto por France et al. (1993). As equações para transformar pressão em volume devem ser feitas para cada condição específica, pois variações têm sido 
encontradas, portanto, recomenda-se que ensaios para correlacionar estes valores sejam feitos para cada laboratório (Bueno, 1998).

Os gases produzidos são proporcionais ao ataque microbiano. Podendo-se medir o volume de gases produzidos, é possível estimar a quantidade de substrato que foi digerido. Fontes alternativas de inóculo têm sido testadas para prover microrganismos similares àqueles obtidos no fluído ruminal, como por exemplo fezes de ruminantes (Maurício et al., 1998; Bueno et al., 1999).

Outra possibilidade apresentada por esta metodologia é a determinação da degradabilidade da matéria seca e/ou orgânica durante a produção de gases. Isso permite que melhor se interprete a cinética fermentativa comparando à taxa de desaparecimento de material, semelhante ao que é feito pela técnica in situ de degradabilidade ruminal desenvolvida por Ørskov \& McDonald (1979).

\subsection{Degradabilidade ruminal in situ}

Por ser uma técnica simples e econômica, a degradabilidade ruminal in situ ou in sacco proporciona estimar mais facilmente o valor nutricional dos alimentos para ruminantes, sendo possível estimar a degradabilidade potencial do alimento em estudo (Ørskov \& McDonald, 1979). A técnica na verdade mede o desaparecimento do substrato, seja por degradação microbiana, hidrólise ou simples solubilização. É um método bastante difundido e seus parâmetros servem como base de cálculo para uma grande gama de dados aos quais apresentaram fortes correlações (Agricultural and Food Research Council, 1993).

Devido a sua ampla utilização, foram feitas diversas pesquisas com o intuito de se estabelecer padrões apropriados e uniformizar a técnica in situ, 
com a finalidade de se obter uma melhor repitibilidade em relação aos resultados, como a porosidade do tecido, tamanho da partícula, quantidade de amostra, lavagens dos sacos, entre outros.

Apesar dos esforços para a uniformização da técnica, ainda são detectadas diferenças nos resultados entre laboratórios mesmo quando utilizam condições de avaliação identicas (Nocek, 1985). A origem dessas variações é devido às diferenças na fermentação ruminal entre animais, ou no mesmo animal utilizado em dias distintos, ou entre réplicas nos sacos de nylon incubados no mesmo dia e animal (Mehrez \& Ørskov, 1977).

\subsection{Digestibilidade in vitro (Tilley \& Terry)}

Essa técnica de fermentação in vitro proposta por Tilley \& Terry (1963) tem sido largamente utilizada para estimar a digestibilidade in vivo. Nessa técnica existem vários fatores que podem ser causa de variação nos resultados, tais como: espécie do animal doador de inóculo, tipo de dieta e pH do meio, além das diferenças entre as marchas analíticas adotadas por diversos laboratórios (Church \& Petersen, 1960; Grant, 1974).

Duas estimativas de digestibilidade são possíveis com técnicas gravimétricas (capacidade de se estimar desaparecimento do substrato) utilizando um tempo único de incubação com fluído ruminal tamponado: digestibilidade verdadeira e digestibilidade aparente (Goering \& Van Soest, 1970). Estimativas de digestibilidade aparente se baseiam na técnica da digestibilidade in vitro de Tilley \& Terry (1963). O método de Tilley \& Terry simula a digestão ruminal por 48 horas, seguido de uma digestão com pepsina e ácido fraco por 48 horas. O resíduo indigestível, neste caso, inclui resíduos bacterianos e outros materiais insóluveis em pepsina. 
A maior desvantagem dessa técnica é o tempo prolongado de execução das análises, sobre o qual Weiss (1994) argumenta que devido às variações da técnica e do animal doador do fluído ruminal, a utilização de equações para ajustar estimativas de digestibilidade in vitro para valores in vivo deve ser feita para cada laboratório.

A metodologia de digestibilidade verdadeira ou mais conhecida como metodologia dos dois estágios (Goering \& Van Soest, 1975), requer a metade do tempo da Tilley \& Terry e tem a mesma precisão. Neste caso a digestão com pepsina é abolida, já que o resíduo da etapa fermentativa é extraído em detergente neutro. A digestibilidade verdadeira é baseada na extração de toda a matéria microbiana do resíduo da digestão em detergente neutro, resultando em um resíduo constituído apenas de parede celular indisgestível (Van Soest et al., 1991). Uma das vantagens dessa metodologia modificada por Goering \& Van Soest é a possibilidade de avaliação da digestibilidade e do perfil de degradação da parede celular in vitro por conhecimento do conteúdo da fibra em detergente neutro do alimento.Todas essas técnicas in vitro requerem uma padronização usando amostras de alimentos que tenham sido previamente analisadas (in vitro) ou oferecidas como uma única dieta. Contudo, Tamminga \& Williams (1998) apontam que técnicas como a digestibilidade de Tilley \& Terry determinam apenas o ponto final da digestibilidade, ou seja, a cinética talvez fosse mais importante.

\subsection{Estimativa de nutrientes digestíveis totais}

Um dos métodos mais utilizados para avaliar o valor nutritivo dos alimentos é a estimativa de nutrientes digestíveis totais (NDT). Este sistema, 
embora funcional, apresenta algumas desvantagens e necessita ser melhorado (Longo et al., 2000).

A disponibilidade energética é de difícil medição e possui uma grande variação entre os alimentos. Esta dificuldade tem levado muitos pesquisadores a desenvolver métodos e modelos que melhor estimem a real quantidade de energia de uma dieta ou alimento (Bricarello et al., 2000).

Para avaliação geral do valor nutritivo de um alimento por esta metodologia, são usados coeficientes de digestão para cada fração bromatológica (Maynard et al.,1984). Mas para se chegar a uma estimativa mais real, seria preciso deduzir perdas pelas fezes, urina, incremento calórico e, principalmente no caso de ruminantes, perdas gasosas, sendo as duas últimas de difícil medição.

Para isso, Kearl (1982) elaborou uma série de equações para estimativa de NDT em função da análise bromatológica:

- para palhas e resíduos fibrosos secos

NDT $(\mathrm{g} / \mathrm{kg} \mathrm{MS})=-172,649+1,2120 \times \mathrm{PB}+0,8352 x \mathrm{ENN}+2,4637 x E E+0,4475 x \mathrm{FB}$

- para pastagens e forragens frescas

NDT $(\mathrm{g} / \mathrm{kg} \mathrm{MS})=-217,656+1,4284 x \mathrm{~PB}+1,0277 x \mathrm{xNN}+1,2321 x E E+0,4867 x \mathrm{FB}$

- para silagens de volumosos

NDT $(\mathrm{g} / \mathrm{kg} \mathrm{MS})=+219,391+1,0538 \times \mathrm{PB}+0,9736$ XENN+3,0016XEE+0,4590xFB

- para alimentos energéticos ( $P B<200 \mathrm{~g} / \mathrm{kg} M S$ e $F B<180 \mathrm{~g} / \mathrm{kg} M S)$

NDT $(\mathrm{g} / \mathrm{kg} \mathrm{MS})=+402,625+0,1969 \times \mathrm{PB}+0,4228 \times \mathrm{ENN}+1,1903 \times \mathrm{EE}-0,1379 \times \mathrm{FB}$

- para alimentos protéicos (PB>200g/kg MS)

NDT $(\mathrm{g} / \mathrm{kg} \mathrm{MS})=+403,227+0,5398 x P B+0,4448 x E N N+1,4223 x E E-0,7007 x F B$

onde: $\mathrm{NDT}=$ teor de nutrientes digestíveis totais; $\mathrm{PB}=$ teor de proteína bruta; $\mathrm{ENN}$ = teor de extrativo não nitrogenado; $\mathrm{EE}=$ teor de extrato etéreo e $\mathrm{FB}=$ teor de fibra bruta(todos os valores são experesso em $\mathrm{g} / \mathrm{kg}$ de MS). 


\section{MATERIAL E MÉTODOS}

\subsection{Local e animais}

O experimento foi desenvolvido no Laboratório de Nutrição Animal do Centro de Energia Nuclear na Agricultura da Universidade de São Paulo (LANA/CENA/USP).

Como doadores de líquido do rúmen, foram utilizados seis ovinos da raça Santa Inês, machos, adultos, castrados e providos de cânula ruminal permanente.

A alimentação dos animais doadores foi constituída de pastagem de gramínea cultivada e uma suplementação ao final do dia com feno de Tifton, concentrado comercial e sal mineral à vontade, conforme os requisitos mínimos para manutenção corporal de ovinos pesando aproximadamente $70 \mathrm{~kg}$ (AFRC, 1993).

\subsection{Substratos}

Os substratos utilizados foram: milho grão (Zea mays), silagem de milho, farelo de soja, feno de alfafa (Medicago sativa) e capim colonião (Panicum maximum - um controle interno utilizado pelo Laboratório de Nutrição Animal-LANA/CENA/USP). Os substratos foram secos a $60^{\circ} \mathrm{C}$, moídos em 
moinho de Wiley utilizando peneira com perfurações de $1 \mathrm{~mm}$ e $2 \mathrm{~mm}$ e posteriormente armazenados em frascos plásticos com tampa vedante.

\subsection{Análise bromatológica}

Foram determinados os teores de: matéria seca (MS), matéria mineral (MM), extrato etéreo (EE), fibra bruta (FB) e proteína bruta (PB) (AOAC, 1995). Também foram determinados os teores de fibra em detergente neutro (FDN) e fibra em detergente ácido (FDA) (Van Soest \& Wine, 1967), além da estimativa de NDT (Kearl, 1982) para melhor caracterizar os substratos .

\subsection{Síntese microbiana através da incorporação de radiofósforo}

A técnica proposta por Van Nevel \& Demeyer (1977) e adaptada ao LANA/CENA/USP, consistiu na preparação de 3 tubos próprios para centrífuga refrigerada Sorvall (mod. RC2-B), com $1 \mathrm{~g}$ de MS do substrato a ser testado. Cada tubo recebeu $4 \mathrm{ml}$ de solução tamponante $(25 \mathrm{~g}$ de glucose e $3 \mathrm{~g}$ de bicarbonato de sódio por litro), $16 \mathrm{ml}$ do inóculo e, por fim, $25 \mu \mathrm{l}$ de solução de radiofósforo na forma de fosfato, correspondendo a $0,1 \mu \mathrm{Ci}$ de ${ }^{32} \mathrm{P}$.

Imediatamente após a adição do radiofósforo, a atividade microbiana de um dos três tubos foi paralisada com $1 \mathrm{ml}$ de ácido sulfúrico $\left(\mathrm{H}_{2} \mathrm{SO}_{4}\right) 18 \mathrm{~N}$. Os tubos foram incubados à temperatura constante de $39^{\circ} \mathrm{C}$ com saturação de gás carbônico por um período de 8h, conforme proposto por Bueno (1998). Terminada a incubação, os outros dois tubos também receberam $1 \mathrm{ml}$ de $\mathrm{H}_{2} \mathrm{SO}_{4}$ $18 \mathrm{~N}$ para que a síntese microbiana fosse interrompida.

Para avaliar a incorporação do ${ }^{32} \mathrm{P}$, os tubos foram levados à centrífuga refrigerada Sorvall e submetidos à centrifugação por 10 minutos, 
separando-se o material em precipitado e sobrenadante. Para a determinação da radioatividade no material, $1 \mathrm{ml}$ do sobrenadante foi transferido para frascos de cintilação líquida, completando-se o volume para $20 \mathrm{ml}$ com água destilada, e levados para contagem em cintilador líquido (Packard mod. 1600 TR) por dois minutos cada. O restante das amostras foi armazenado em congelador para posterior análise de fósforo inorgânico $(P)$, de acordo com a metodologia de Fiske \& Subbarow (1925).

O precipitado foi lavado com solução salina $0,85 \%$ para eliminação do radiofósforo extracelular, e o restante do sobrenadante descartado. Ao final das lavagens ressuspendeu-se o precipitado com água destilada e este foi transferido para cadinho de porcelana e levado para secagem em estufa de $105^{\circ} \mathrm{C}$, até peso constante do material, sendo possível a determinação da matéria seca. Após a pesagem, o material foi incinerado e por um período de 90 minutos sofreu uma digestão ácida. O material digerido foi transferido para frascos de cintilação líquida e levado para contagem conforme descrito anteriormente.

\subsubsection{Preparo do inóculo}

Foram testados dois tipos de inóculos, um contendo apenas a parte líquida do conteúdo ruminal e o outro a parte líquida e sólida em iguais proporções.

A fase líquida do conteúdo ruminal foi coletada com o auxílio de uma sonda adaptada à uma seringa. A parte sólida (particulados) foi coletada com o auxílio de uma pinça, através da cânula ruminal, diretamente no rúmen do animal. Ambas as fases foram armazenadas em garrafas térmicas préaquecidas $\left(39^{\circ} \mathrm{C}\right)$ e vedadas hermeticamente. 
No laboratório, o líquido do rúmen foi filtrado em gaze esterilizada para a separação de partículas grosseiras, sendo em seguida inoculado juntamente com o substrato em cada tubo.

O inóculo que continha ambas as fases foi preparado com medidas iguais das partes líquida e sólida ( $50 \%$ fase líquida e $50 \%$ fase sólida) e processados em liquidificador por um período de 10 segundos. Em seguida esse material foi filtrado em fralda de tecido, onde apenas o filtrado foi utilizado e inoculado juntamente com o substrato.

\subsubsection{Separação da massa microbiana}

A função da centrifugação foi precipitar os microrganismos e facilitar a separação destes do resíduo de alimento que ficou misturado. As rotações testadas nesse experimento corresponderam à uma força gravitacional de $12.317 \mathrm{~g}$ (10.000 rpm) e $39.907 \mathrm{~g}$ (18.000 rpm).

\subsubsection{Número de lavagens}

Procurando conseguir que o marcador não incorporado pelos microrganismos (extracelular) fosse removido o mais eficientemente possível para que não interferisse na atividade radioativa da massa microbiana, foram testados diferentes números de lavagens: duas, três e quatro. As lavagens foram feitas com solução salina $0,85 \%$ visando remover o excesso de fósforo marcado localizado extracelularmente que estava contaminando a massa microbiana. 


\subsection{Produção de gases}

A técnica de produção de gases in vitro foi conduzida de acordo com Maurício et al. (1999). Consistiu na incubação de aproximadamente $1 \mathrm{~g}$ de MS do alimento a ser testado em garrafas vedadas, onde adicionou-se $90 \mathrm{ml}$ de um meio contendo minerais e tamponantes e $10 \mathrm{ml}$ de inóculo. A intervalos prédeterminados $(0,3,6,9,12,15,18,22,26,30,34,40,48,60,72$ e 96h), a pressão dos gases produzidos através das fermentações microbianas foi medida utilizando um "transducer". Após o término da incubação, as garrafas foram colocadas em água com gelo com a finalidade de paralisar a síntese microbiana. O material foi filtrado em cadinho sinterizado de peso conhecido, em seguida seco em estufa à uma temperatura de $105^{\circ} \mathrm{C}$, até peso constante, e posteriormente incinerado, determinando assim a matéria orgânica digerida no processo fermentativo, conforme proposto por France et al. (1993); Theodorou et al. (1994); Blümmel et al. (1997a) e Maurício et al. (1999).

Os resultados obtidos na metodologia de produção de gases foram avaliados de acordo com o modelo de France et al. (1993). Os parâmetros de comparação foram lag time (LAG), potencial de produção de gases (POT), degradabilidade de matéria seca in vitro (DEG), volume de gases produzidos após 48h (G48) e 96h (G96), razão entre G48 e G96 (REL1) e entre G96 e POT (REL2). Esses dois últimos parâmetros foram inclusos para se entender quais proporções dos gases foram produzidas após 48h comparando com o total de gases produzidos (G96), e quão parecido foi a produção de gases após 96h do potencial total de gás produzido (Bueno et al., 2000, 2001). 


\subsubsection{Coleta do inóculo}

A coleta do líquido ruminal foi realizada através de uma sonda acoplada à uma seringa com o auxílio de uma pinça, através da cânula ruminal, foi coletada a fração mais sólida (particulados). O material coletado foi colocado em potes herméticos, previamente preenchidos com $\mathrm{CO}_{2}$ a uma temperatura de $39^{\circ} \mathrm{C}$.

No laboratório esse material foi homogeneizado em liqüidificador por alguns segundos nas proporções a serem analisadas. Após o processamento, esse inóculo foi filtrado em 3 fraldas de algodão espremendo-se ao máximo, separando a parte sólida da líquida. O substrato e a solução nutritiva foram inoculados nas garrafas de incubação.

\subsubsection{Preparo do inóculo}

Quatro tipos de inóculos foram preparados com diferentes proporções das fases sólida e líquida do conteúdo ruminal. Inóculo A contendo $100 \%$ de fase líquida e $0 \%$ de fase sólida; inóculo B, $75 \%$ de fase líquida e 25\% de fase sólida; inóculo C, $67 \%$ de fase líquida e 33\% de fase sólida; inóculo D, $50 \%$ de fase líquida e $50 \%$ de fase sólida.

\subsection{Degradabilidade in vitro da matéria seca}

Durante o ensaio de produção de gases, em períodos prédeterminados $(0,3,9,15,26,48,72$ e 96h), as garrafas de incubação foram colocadas em água com gelo, abertas, e seu conteúdo filtrado em cadinhos sinterizados de peso previamente conhecido. Os cadinhos permaneceram em 
estufa a $105^{\circ} \mathrm{C}$, até peso constante. A diferença entre pesos possibilitou estimar a quantidade de MS do resíduo. Os resultados foram ajustados pelo modelo exponencial de Ørskov \& McDonald (1979) com as modificações de McDonald (1981).

\subsection{Degradabilidade in situ}

Consistiu na pesagem de $3 \mathrm{~g}$ de substrato seco e moído, inseridos em sacolas de nylon previamente pesadas, realizando três repetições para cada substrato. As repetições foram incubadas no rúmen de três animais diferentes, por um período de incubação de 3, 8, 16, 24, 48, 72 e 96h. Também foram preparadas sacolas de nylon para determinar a perda por lavagem e teor da matéria seca. Durante este período os animais em experimento foram alimentados com uma dieta contendo $80 \%$ de volumoso (forragem verde e feno) e $20 \%$ de concentrado comercial, similar àquela dos substratos a serem testados.

As sacolas foram presas em alças adaptadas que permitiam a sua movimentação no rúmen do animal, e estas, presas às rolhas das cânulas quando introduzidas no rúmen. Ao término de cada incubação, a sacola retirada foi imediatamente colocada em água com gelo, a fim de cessar a atividade microbiana. Em seguida, lavadas em água corrente para a retirada de impurezas externas, e então desamarradas e armazenadas em congelador.

Ao terminar todo o período de incubação, as sacolas foram lavadas em máquina automática, assim como as sacolas preparadas para determinação de MS e perda por lavagem. Todas foram secas em estufas com circulação forçada de ar, a uma temperatura constante de $60^{\circ} \mathrm{C}$, até peso constante. Por diferença de pesagem possibilitou estimar a degradabilidade da MS. 
Os resultados da degradabilidade ruminal in situ foram processados pelo software Neway Excel, desenvolvido pelo Rowett Research Institute, Aberdeen, Escócia, fornecendo os parâmetros do modelo de degradabilidade $\left(p=a+b\left(1-e^{-c t}\right)\right.$ de Ørskov \& McDonald (1979), onde $p$ representa a degradação da MS no tempo $t,(a+b)$ a taxa de degradação, e $a, b$ e $c$ são constantes da equação exponencial.

\subsection{Digestibilidade in vitro (Tilley \& Terry)}

Em um tubo plástico, foram pesados aproximadamente $500 \mathrm{mg}$ do substrato previamente seco. Em cada tubo adicionou-se $40 \mathrm{ml}$ de uma solução tamponante, preparada no dia anterior à coleta do líquido ruminal. Após a coleta do líquido do rúmen em garrafas hermeticamente vedadas, adicionou-se em cada tubo $12 \mathrm{ml}$ do líquido ruminal devidamente filtrado em gaze. Passou-se gás carbônico sobre a superfície de cada tubo e estes foram imediatamente vedados com rolhas equipadas com válvulas de Bunsen. Incubou-se por $48 \mathrm{~h}$ à $39^{\circ} \mathrm{C}$, em incubadora de temperatura controlada. Os tubos foram agitados levemente por pelo menos três a quatro vezes durante a fermentação para eliminar os gases formados.

Após a incubação, adicionou-se em cada tubo $1 \mathrm{ml}$ de tolueno com a finalidade de cessar a digestão. Em seguida, o resíduo foi tratado com detergente neutro por 1h (Goering \& Van Soest, 1970) e filtrado em cadinho sinterizado de peso conhecido. Os cadinhos foram secos em estufas de $105^{\circ} \mathrm{C}$ até peso constante. Por diferença de peso dos cadinhos, foi possível determinar a digestibilidade in vitro da MS (DIVMS, \%). 


\subsection{Análise estatística}

Para a realização do experimento foi utilizado um delineamento inteiramente casualizado, onde todos os substratos foram avaliados para cada uma das variáveis com pelo menos três repetições no tempo, sendo os resultados caracterizados quanto à média e desvio padrão. Cada variável, foi comparada por análise de variância considerando a hipótese de nulidade dentro de cada substrato.

As correlações entre as metodologias foram testadas quando biologicamente significante e compatíveis. Os dados foram avaliados pelo software "SAS for Windows" (SAS, 2000). Dentre as metodologias analisadas, buscou-se correlacionar os principais parâmetros dois a dois, considerando significativas as correlações com valor de $\mathrm{P}$ menor que $5 \%$.

Tabela 1. Análise de variância para cada um dos ensaios deste experimento

\begin{tabular}{lcccc}
\hline \multirow{2}{*}{ fontes de variação } & \multicolumn{4}{c}{ graus de liberdade } \\
\cline { 2 - 5 } & ensaio 1 & ensaio 2 & ensaio 3 & ensaio 4 \\
\hline amostras & 4 & 4 & 4 & 4 \\
repetições & 2 & 2 & 2 & 2 \\
tratamentos & 3 & 1 & 1 & 2 \\
erro & 50 & 22 & 22 & 36 \\
\hline total & 59 & 29 & 29 & 44 \\
\hline
\end{tabular}

$\mathrm{Na}$ Tabela 1, é demonstrado os graus de liberdade usados para análise de variância para cada ensaio testado neste trabalho, sendo eles: ensaio 1 - teste de inóculo usado na técnica in vitro de produção de gases, ensaio 2 - teste de inóculo usado na técnica in vitro de incorporação de ${ }^{32} \mathrm{P}$, ensaio 3 - teste de velocidade de centrifugação para separação da massa 
microbiana (técnica in vitro de incorporação de ${ }^{32} \mathrm{P}$ ) e ensaio 4 - teste do número de lavagens para descontaminação da massa microbiana (técnica in vitro de incorporação de ${ }^{32} \mathrm{P}$ ). 


\section{RESULTADOS E DISCUSSÃO}

\subsection{Análise bromatológica}

Os resultados da análise bromatológica dos substratos estudados apresentaram diferença $(P<0,01)$ entre as variáveis testadas. Essas diferenças podem ser visualizadas através das médias apresentadas na Tabela 2. Em vista da variação nos constituintes nutricionais, os substratos testados puderam ser divididos em fibrosos (feno de alfafa e capim colonião), concentrados (milho grão e farelo de soja) e fermentado (silagem de milho); caracterizando assim uma confiável variabilidade entre os substratos para testarem as diferentes metodologias/procedimentos propostos.

Os resultados apresentados na Tabela 2 estão de acordo com o NRC (2000). Os teores de PB, FDN e FDA para o milho grão apresentaram valores acima do encontrado pela literatura, que são: 4,2; 9,5 e $3,4 \%$ respectivamente. Os teores de FDA e EE para silagem de milho encontrados na literatura citada foram de $54,1 \%$ e $2,3 \%$ respectivamente, sendo esses valores pouco diferentes dos apresentados na Tabela 2. O capim colonião, por ser um substrato de controle interno do LANA/CENA/USP, apresentou resultados semelhantes ao banco de dados do laboratório. 
Tabela 2. Resultados da análise bromatológica* para os diferentes substratos utilizados.

\begin{tabular}{lcccccccc}
\hline substrato & $M S^{*}$ & $M M^{*}$ & $N D T^{* *}$ & $E E^{*}$ & $F B^{*}$ & $F D N^{*}$ & $F D A^{*}$ & $P B^{*}$ \\
\hline milho grão & 93,8 & 16,4 & 81,5 & 69,4 & 61,9 & 177,9 & 44,4 & 92,9 \\
silagem de milho & 27,8 & 54,9 & 64,0 & 35,3 & 268,4 & 378,5 & 308,1 & 72,6 \\
feno de alfafa & 43,3 & 82,0 & 60,0 & 35,2 & 313,8 & 335,2 & 329,6 & 186,6 \\
capim colonião & $\mathrm{nd}^{* \star *}$ & 73,0 & 50,8 & 27.6 & 461,7 & 484,2 & 480,6 & 43,3 \\
farelo de soja & 88,2 & 62,9 & 94,7 & 28,2 & 112,6 & 157,8 & 106,0 & 459,4 \\
\hline e.p.m. .** $^{* \star 2}$ & 2,28 & 0,55 & 11,05 & 1,00 & 18,92 & 7,36 & 3,50 & 2,09 \\
\hline
\end{tabular}

* MS expressa em $\mathrm{g} / \mathrm{kg}$ de matéria verde e os demais valores expressos em $\mathrm{g} / \mathrm{kg}$ de MS.

** NDT: estimativa de nutrientes digestíveis totais (\%)

*** nd: valor não determinado

**** epm: erro padrão entre as médias

\subsection{Síntese microbiana através da incorporação in vitro de radiofósforo}

\subsubsection{Inóculo}

Os resultados observados em relação as diferentes proporções de inóculo são mostrados na Figura 1, onde não foi observada diferença significativa $(P>0,05)$ entre os inóculos testados. Estes resultados provavelmente estejam relacionados ao fato de os substratos terem uma quantidade/qualidade de fibra, na qual as frações sólida e líquida do inóculo conteúdo do rúmem suprem com maior eficiência os microrganismos celulolíticos para a fermentação do alimento. 


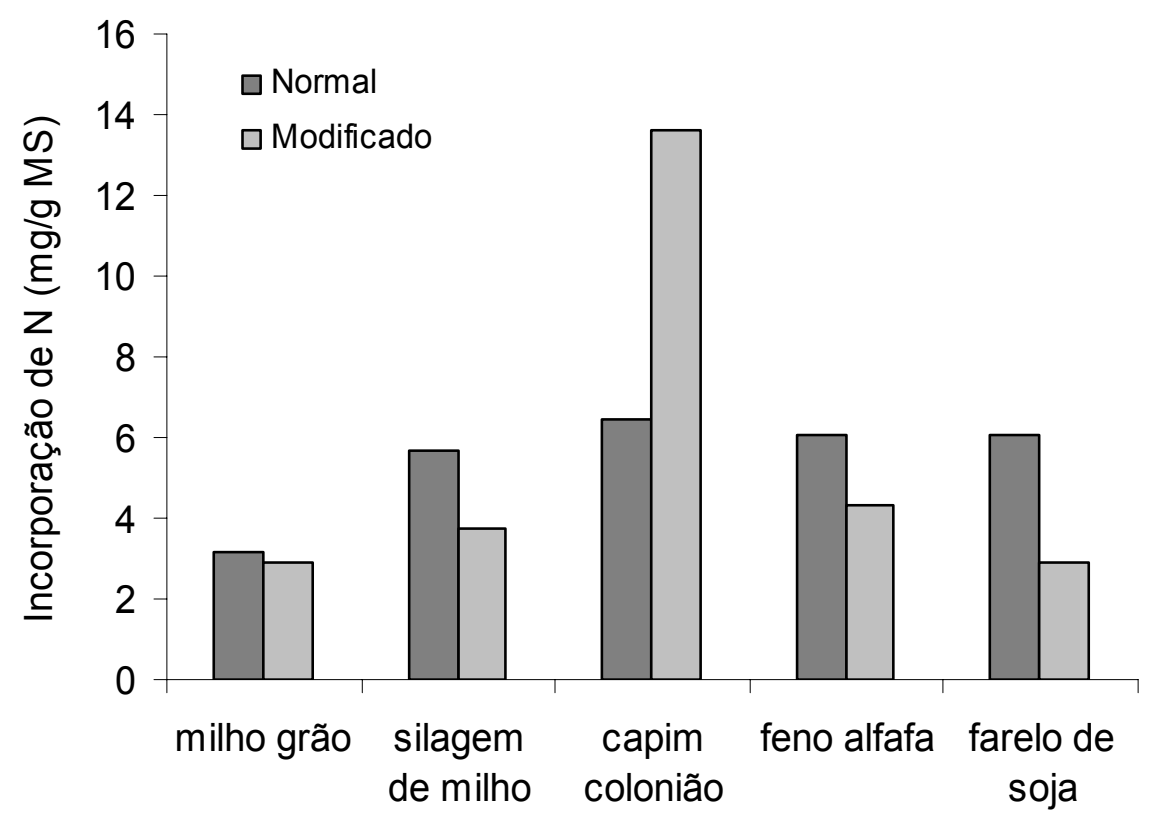

Figura 1. Diferenças na determinação de incorporação de $N$ pelos microrganismos ruminais, comparando diferentes proporções de inóculos.

\subsubsection{Separação da massa microbiana}

Os resultados obtidos em relação à velocidade de centrifugação (10.000 e 18.000rpm), estão mostrados na Figura 2. Estatisticamente não houve diferenças significativas $(P>0,05)$ entre as velocidades de centrifugação testadas, o que se pôde observar é um melhor manuseio das amostras quando se utiliza uma centrifugação com força gravitacional maior. 


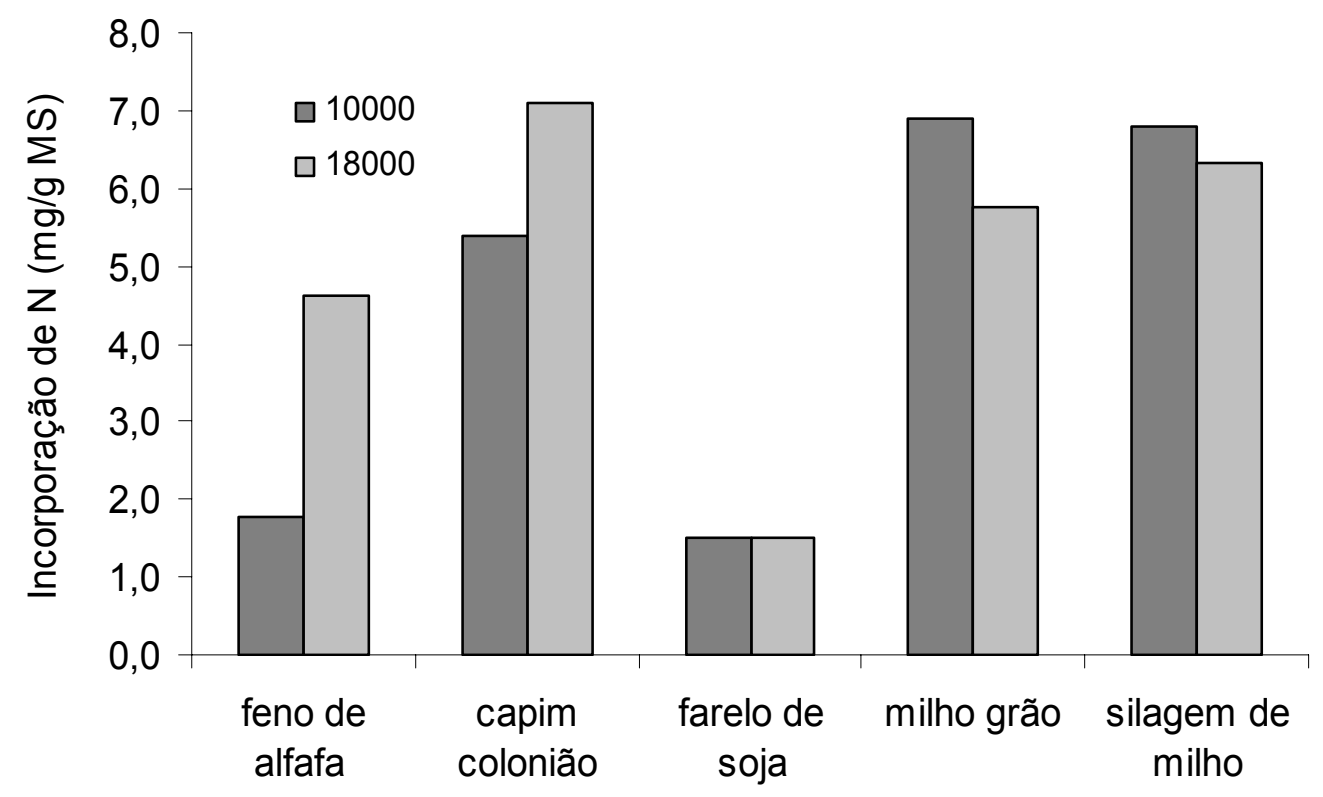

Figura 2. Diferenças na determinação de incorporação de $N$ pelos microrganismos ruminais, usando-se rotação de 10000 e 18000 rpm para separação da massa microbiana.

\subsubsection{Número de lavagens}

Os resultados em relação ao número de lavagens testado (2, 3 e 4) das atividades residuais para cada substrato são mostrados na Tabela 3. Notase uma forte tendência de diminuição da atividade e, por conseqüência, da contaminação com o aumento do número de lavagens. Isto mostra que aumentando 0 número de lavagens, consegue-se uma melhor descontaminação da massa microbiana, permitindo uma maior sensibilidade na técnica. 
Tabela 3. Eficiência de descontaminação (em \%) de radiofósforo extracelular, usando 3 ou 4 lavagens, em relação ao uso de duas lavagens.

\begin{tabular}{lcc}
\hline \multirow{2}{*}{ substratos } & \multicolumn{2}{c}{ eficiência de descontaminação } \\
\cline { 2 - 3 } & 3 lavagens & 4 lavagens \\
\hline milho grão & 76,7 & 80,7 \\
silagem de milho & 68,4 & 88,7 \\
feno alfafa & 64,7 & 88,6 \\
capim colonião & 70,4 & 96,1 \\
farelo de soja & 54,4 & 86,8 \\
média geral $^{*}$ & $65,9^{\mathrm{b}}$ & $85,7^{\mathrm{a}}$ \\
epd $^{* *}$ & 2,35 & 2,81 \\
\hline
\end{tabular}

" médias com sobrescritos diferentes indicam diferença significativa pelo teste de Tukey, ao nível de $5 \%$ de probabilidade.

** epd = erro padrão da diferença entre as médias.

O número de lavagens suficiente para uma completa remoção dos contaminantes não necessitaria ser maior que quatro, uma vez que a eficiência da descontaminação neste caso chega próximo a 100\% (capim colonião 96,1\%) e difere estatisticamente de três lavagens $(P<0,05)$, chegando a um melhor resultado do que o testado por Vitti \& Silva Filho (1985).

\subsection{Produção de gases}

\subsubsection{Preparo do inóculo}

Os resultados da matéria seca (MS) das diferentes proporções de inóculo testados foram: 21,0;23,7; 24,3 e 25,9g/kg, respectivamente para 
inóculos $A, B, C$ e $D$. Os resultados do lag time para cada um dos substratos estão apresentados na Tabela 4.

Tabela 4. Lag time dos seis substratos testados para cada inóculo*.

\begin{tabular}{lccccc}
\hline \multirow{2}{*}{ substratro } & \multicolumn{5}{c}{ lag time $(h)^{* *}$} \\
\cline { 2 - 6 } & $A$ & $B$ & $C$ & $D$ & significância \\
\hline milho grão & $5: 32$ & $3: 57$ & $5: 04$ & $4: 55$ & $\mathrm{~ns}$ \\
silagem milho & $6: 07$ & $6: 13$ & $6: 25$ & $6: 02$ & $\mathrm{~ns}$ \\
feno alfafa & $7: 28^{\text {ab }}$ & $7: 37^{\mathrm{a}}$ & $7: 24^{\mathrm{b}}$ & $7: 20^{\mathrm{b}}$ & $<0.01$ \\
capim colonião & $6: 31$ & $6: 28$ & $6: 34$ & $7: 07$ & $\mathrm{~ns}$ \\
farelo soja & $0: 28$ & $0: 16$ & $0: 39$ & $0: 05$ & $\mathrm{~ns}$ \\
\hline
\end{tabular}

* inóculos: $A$ (somente fase líquida); $B$ ( $25 \%$ fase sólida e $75 \%$ fase líquida); C (33\% fase sólida e $67 \%$ fase líquida); $D$ ( $50 \%$ fase sólida e $50 \%$ fase líquida)

${ }^{*}$ médias com diferentes sobrescritos, nas linhas, diferem entre si (Tukey; $\left.\mathrm{P}<0,05\right) . n s=$ não significativo

O lag time (LAG) não mostrou diferença significativa $(P>0,05)$ para 0 efeito do inóculo, mas significativa para o substrato $(P<0,01)$. Isso é compreensível para os tipos de substratos diferentes e, por esta razão, a interação inóculo*substrato obteve diferença significativa $(P<0,01)$. $O$ feno de alfafa obteve um curto lag time com a inclusão da fase sólida no inóculo. Isso demonstra que a fase sólida do líquido ruminal pode suprir com maior eficiência os microrganismos celulolíticos para a fermentação do alimento.

Pela cinética fermentativa (Figura 3) pode ser observado que em alimentos contendo baixo teor de fibra (principalmente milho grão) há uma alta produção de gases utilizando-se o inóculo $A$ (sem a fase sólida). Isso pode ser explicado pela pequena contribuição das fibras na produção total de gases, ocorrendo igualmente para lag time (LAG), onde a produção total de gases, 
após 96h (G96), não obteve diferença significativa para inóculo $(P>0,05)$, mas foi significativa para substrato e para a interação inóculo*substrato $(P<0,01)$.
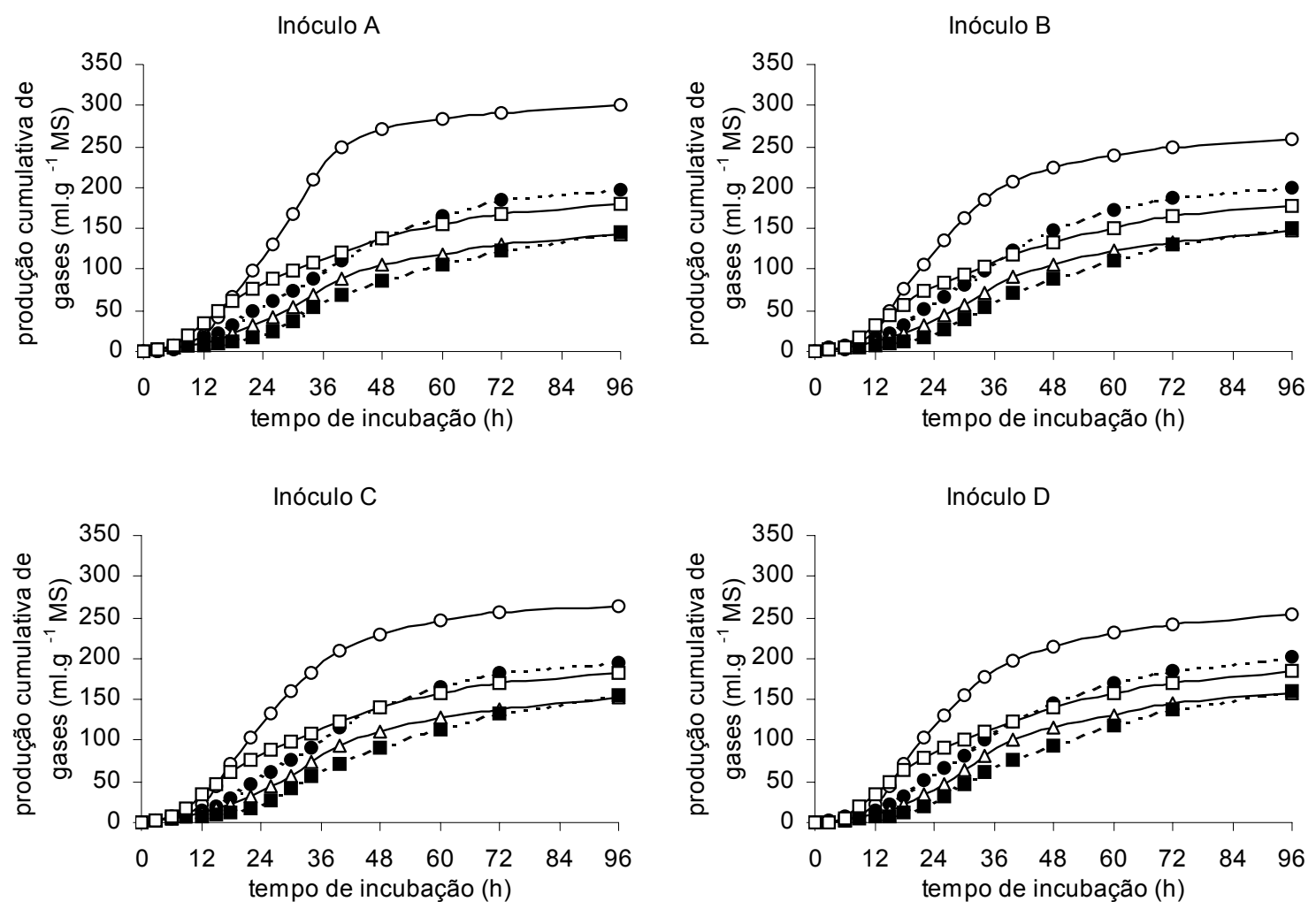

Figura 3 Cinética da produção de gases usando líquido ruminal como fonte de inóculo, com quatro concentrações diferentes de fase sólida $(A=0 \%$, $B=25 \%, C=33 \%$ e $D=50 \%$ ). Legenda: alfafa $(\triangle)$, colonião ( $\mathbf{\bullet})$, farelo de soja $(\square)$, milho grão (०) e silagem de milho $(\bullet)$.

O potencial de produção de gases (POT) (Tabela 5) foi melhor no inóculo $A$ que diferiu significamente $(P<0,01)$ dos inóculos $B, C$ e $D$. $O$ inóculo de melhor degradação (DEG) de substratos foi o $D(P<0,01)$. $A$ REL1 não foi significativa $(P>0,05)$ mas a REL2 foi melhor para o inóculo $B$. Esses fatores 
permitem a interpretação de que usando o inóculo com maior porcentagem de fase sólida, o processo fermentativo foi mais parecido ao potencial de produção de gases (POT).

Tabela 5 Médias das variáveis de produção de gases in vitro incluindo quantias de fase sólida de líquido ruminal*.

\begin{tabular}{|c|c|c|c|c|c|c|}
\hline inóculo & $\begin{array}{c}P O T \\
\left(m l . g M S^{-1}\right)\end{array}$ & $\begin{array}{c}D E G \\
\left(g \cdot k g^{-1}\right)\end{array}$ & $\begin{array}{c}G 48 \\
\left(m l . g M S^{-1}\right)\end{array}$ & $\begin{array}{c}G 96 \\
\left(m l . g M S^{-1}\right)\end{array}$ & $\begin{array}{c}\text { REL1 } \\
\text { (\%) }\end{array}$ & $\begin{array}{c}R E L 2 \\
(\%)\end{array}$ \\
\hline$A$ & $208.9^{a}$ & $725.2^{b}$ & 148.0 & 193.5 & 74.0 & $92.0^{\mathrm{b}}$ \\
\hline$B$ & $200.9^{b}$ & $716.0^{\mathrm{c}}$ & 140.1 & 187.7 & 73.0 & $93.5^{b}$ \\
\hline$C$ & $203.9^{b}$ & $715.1^{\mathrm{c}}$ & 142.6 & 190.1 & 73.4 & $93.4^{b}$ \\
\hline$D$ & $202.2^{b}$ & $730.1^{a}$ & 142.1 & 191.8 & 73.0 & $94.5^{\mathrm{a}}$ \\
\hline significância & $<0.01$ & $<0.01$ & ns & ns & ns & $<0.01$ \\
\hline epd $^{* *}$ & 2,23 & 2,40 & 2,12 & 1,98 & 0,00 & 0,00 \\
\hline
\end{tabular}

*médias com diferentes sobrescritos, nas colunas, diferem entre si (Tukey; $\mathrm{P}<0,05) . n s=$ não significativo.

** epd: erro padrão da diferença entre as médias

Quando se compara diferentes fontes de inóculo para a técnica in vitro de produção de gases, os dados obtidos com trabalhos utilizando ovinos são geralmente extrapolados para bovinos, esses valores foram encontrados por Bueno et al. (1999), que constataram correlações positivas com valores de $r^{2}>0,90(P<0,05)$ para diferentes parâmetros (produção de gases, lag time e digestibilidade in vitro). Em estudos com bovinos, El-Meadaway et al. (1998) compararam a eficácia dos inóculos do líquido do rúmen com uma solução de fezes com vários níveis de diluição (3, 6 e 9\%) para a determinação da digestibilidade in vitro e da produção de gases in vitro. Foi possível concluir que os valores para digestibilidade in vitro (DIVMS) da matéria seca para os inóculos de líquido do rúmen e fezes diluída à $3 \%$ não apresentaram diferença 
significativa $(P>0,05)$. Entretanto a DIVMS foi menor $(P<0,05)$ quando comparada com solução de fezes diluída à 6 ou $9 \%$ e líquido ruminal.

\subsection{Degradabilidade ruminal in situ e in vitro}

As constantes de degradabilidade foram analisadas de acordo com o modelo matemático desenvolvido por Ørskov \& McDonald (1979) com as modificações de McDonald (1981), podendo ser observadas nas Tabelas 6 e 7.

Tabela 6 Estimativa da degradabilidade ruminal in situ dos alimentos testados.

\begin{tabular}{lcccccc}
\hline \multicolumn{1}{c}{ substrato } & $A^{*}$ & $B^{*}$ & $C^{*}$ & Lag $^{*}$ & $A+B^{*}$ & $D E 2 \%^{*}$ \\
\hline milho grão & 16,4 & 78,5 & 0,081 & 0,36 & 94,9 & 78,8 \\
silagem milho & 36,2 & 43,1 & 0,034 & 0,00 & 79,3 & 63,6 \\
feno alfafa & 28,7 & 45,7 & 0,073 & 0,62 & 74,3 & 54,0 \\
capim colonião & 16,7 & 42,6 & 0,036 & 0,95 & 59,3 & 43,6 \\
farelo soja & 34,0 & 63,7 & 0,179 & 0,95 & 97,7 & 89,8 \\
\hline epd** & 5,4 & 8,2 & 0,19 & 0,81 & 7,0 & 7,7 \\
\hline
\end{tabular}

* $A$ - fração prontamente solúvel, em \%; $B$ - fração fermentável insolúvel, em \%; $c$ - taxa de degradação da fração $B$, em $\mathrm{h}^{-1}$; Lag - lag time, em $\mathrm{h} ; A+B$ - degradabilidade potencial, em \%; DE $2 \%$ - taxa de passagem ** epd: erro padrão da diferença entre as médias

Comparando as variáveis testadas nas Tabela 6 e 7, nota-se uma certa diferença para algumas variáveis em relação às técnicas avaliadas. Alguns substratos se destacaram por possuírem uma solubilidade inicial (A) maior (silagem de milho e farelo de soja) ou pelo alto potencial de fermentação (B) (milho grão e farelo de soja) (Tabela 6). 
Como a degradabilidade é calculada a partir de medidas de desaparecimento do material, a explicação provável para a diferença existente entre o $c$ e o Lag é que as sacolas de nylon possuem uma maior porosidade, o que resulta numa maior perda de material não degradado, que por sua vez é considerado degradado (Tabelas 6 e 7).

Tabela 7 Estimativa da degradabilidade ruminal in vitro dos alimentos testados.

\begin{tabular}{lcccccc}
\hline \multicolumn{1}{c}{ substrato } & $A^{*}$ & $B^{*}$ & $C^{*}$ & Lag $^{*}$ & $A+B^{*}$ & $D E 2 \%$ \\
\hline milho grão & 24,0 & 85,6 & 0,022 & 5,59 & 100,0 & 62,4 \\
silagem milho & 17,9 & 90,4 & 0,011 & 8,76 & 100,0 & 43,0 \\
feno alfafa & 22,5 & 42,0 & 0,022 & 3,39 & 64,4 & 43,0 \\
capim colonião & 14,2 & 94,5 & 0,011 & 9,08 & 83,5 & 34,0 \\
farelo soja & 50,3 & 69,3 & 0,023 & 4,61 & 100,0 & 76,0 \\
\hline epd $^{* *}$ & 5,4 & 8,2 & 0,19 & 0,81 & 7,0 & 7,7 \\
\hline
\end{tabular}

* $A$ - fração prontamente solúvel, em \%; $B$ - fração fermentável insolúvel, em \%; $c$ - taxa de degradação da fração $B$, em $\mathrm{h}^{-1} ; \mathrm{Lag}$ - lag time, em $\mathrm{h} ; A+B$ - degradabilidade potencial, em \%; DE 2\%- taxa de passagem ** epd: erro padrão da diferença entre as médias

A cinética da degradabilidade dos alimentos pode ser observada na Figura 4, nota-se que as curvas estão de acordo com o modelo testado para cada metodologia. Observa-se que na metodologia in situ a perda do alimento é maior devido à porosidade das sacolinhas ser maior, por isso seu lag time é superior ao da metodologia in vitro. 

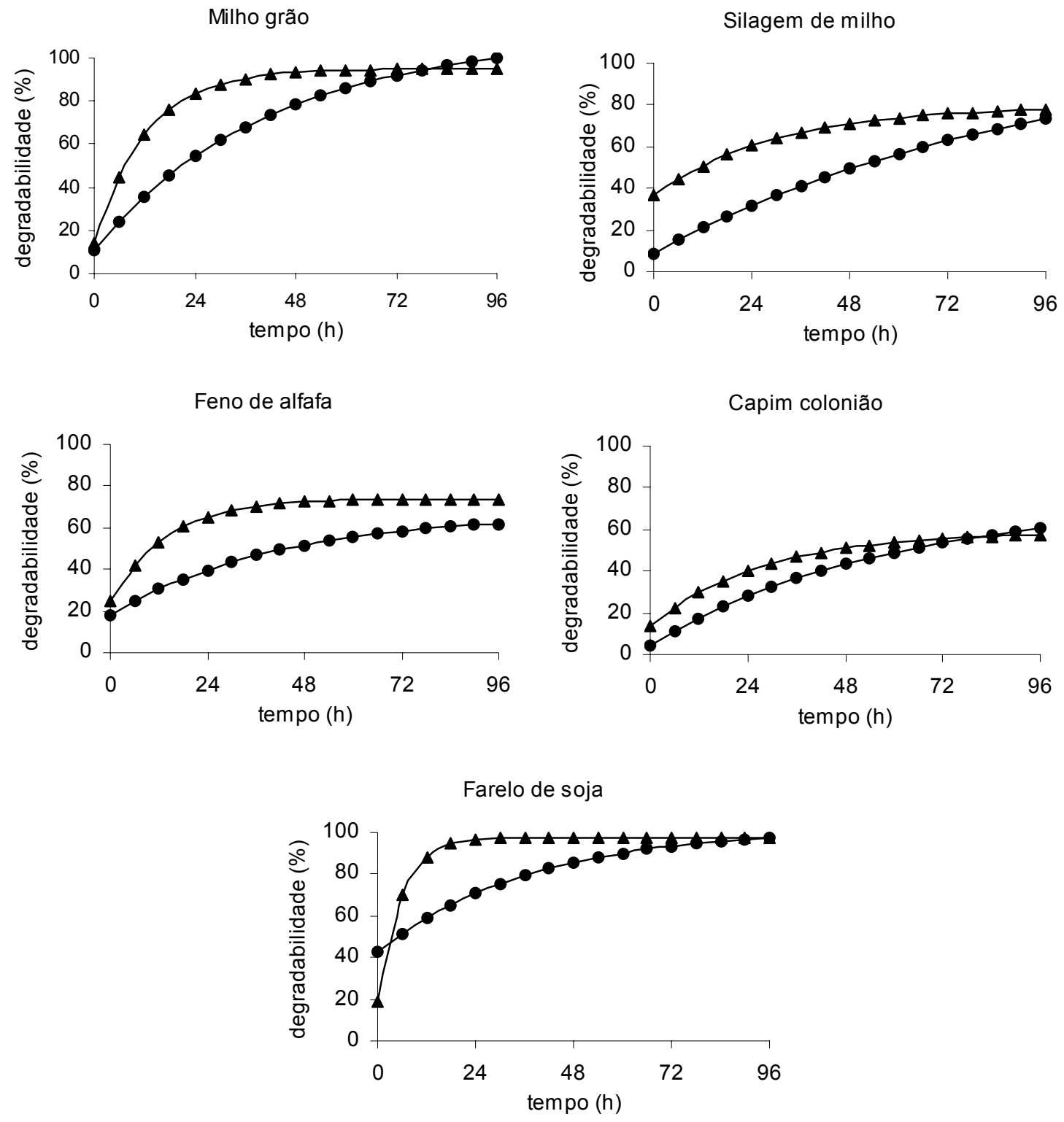

Figura 4 Cinética de degradação ruminal in vitro $(\bullet)$ e in situ (A) dos alimentos testados. 


\subsection{Digestibilidade in vitro (Tilley \& Terry)}

A digestibilidade in vitro da matéria seca (DIVMS \%) dos substratos, pode ser observada na Tabela 8.

Tabela 8. Resultados da digestibilidade in vitro da matéria seca.

\begin{tabular}{ll}
\hline \multicolumn{1}{c}{ substrato } & DIVMS \% \\
\hline milho grão & 83,52 \\
silagem milho & 66,82 \\
feno alfafa & 59,31 \\
capim colonião & 47,79 \\
farelo soja & 94,63 \\
\hline
\end{tabular}

Dados encontrados na literatura de valores de DIVMS (\%) do capim colonião variam entre 45,04 (Weber, 1984) à 63, 9\% (Rocha, 1979), esses valores mostram que os resultados encontrado na Tabela 8 para o mesmo alimento está de acordo com o encontrado na literatura. $\mathrm{O}$ mesmo acontece para o milho grão, para valores encontrados na literatura que variam entre 73,0 (Carvalho, 1980) à 92,9\% (Sobrinho, 1980).

\subsection{Correlações entre as metodologias testadas}

Os resultados apresentados na Figura 5, mostram que as degradabilidades, tanto efetiva $(r=0,96)$ ao fluxo de $2 \%$ quanto a potecial $(r=0,96)$ tem uma correlação positiva $(P<0,01)$ com o NDT. Essa correlação é altamente significativa, reflete o desaparecimento do substrato no rúmen, associando-se de forma direta ao aproveitamento de nutrientes pelo ruminante. 
Esse resultado sugere que os modelos utilizados para a estimativa do NDT (Kearl, 1982) foram confiáveis, inversamente ao que Longo et al. (2000) observaram ao trabalhar com 8 substratos, entre eles silagem de milho e farelo de soja, encontrando um coeficiente de correlação baixo e não significativo $(r=0,50 ; P>0,05)$.

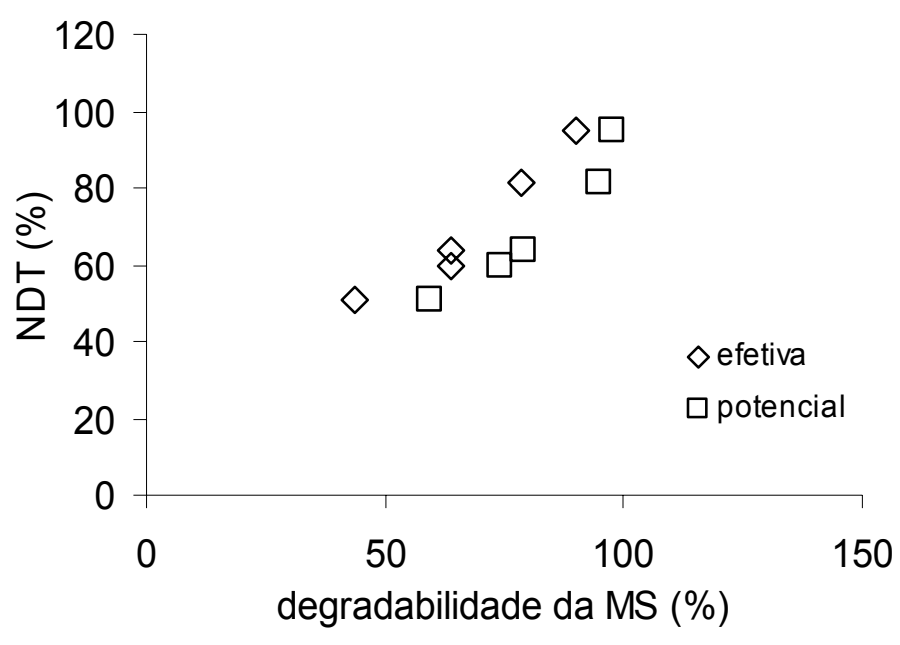

Figura 5. Correlações entre as técnicas de degradabilidade in situ da MS e nutrientes digestíveis totais (NDT \%).

A Figura 6 mostra uma correlação negativa $(P<0,05)$ entre o volume total de gases produzidos em 48h $(r=-0,96)$ e total em 96h $(r=-0,94)$ com o nitrogênio incorporado. Esse resultado foi semelhante ao encontrado por Blümmel et al. (1997b), que obteve uma correlação negativa ( $r=-0,77, P<0,001$ ) quando comparou volume de gases pela técnica in vitro e o crescimento microbiano enriquecido com ${ }^{15} \mathrm{~N}$. A fermentação resultante do ataque microbiano nos substratos é responsável pela produção de gases, estes são diretamente proporcionais ao ataque microbiano. Assim, quando se tem o valor 
do volume de gases produzidos, é possível estimar a quantidade de substrato degradado.

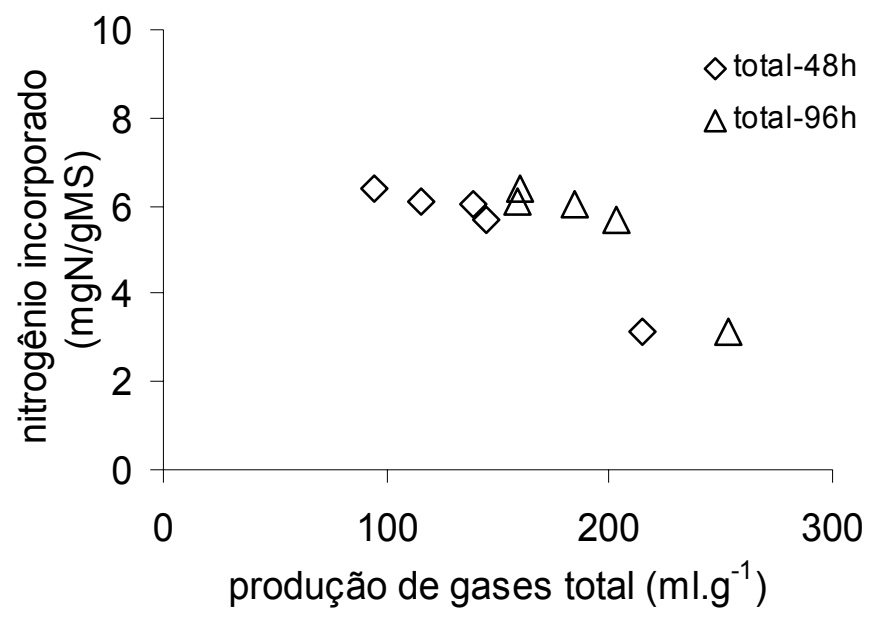

Figura 6. Correlações entre as metodologias de produção total de gases 48 e 96 horas com nitrogênio incorporado ( $\mathrm{mgN} / \mathrm{gMS}$ ).

Correlações negativas $(P<0,01)$ foram encontradas entre os teores de fibras (FB, FDN e FDA) e valores de degradabilidade e digestibilidade (Figura 7). Na Figura 7a, observa-se que a degradabilidade efetiva in situ correlaciona-se negativamente com os teores de FB ( $r=-0,98)$, FDN $(r=-0,96)$ e FDA $(r=-0,97)$. Na Figura $7 b$, observa-se o mesmo quando compara-se a degradabilidade potencial in situ e os teores de FB ( $r=-0,98)$, FDN $(r=-0,96)$ e FDA $(r=-0,98)$. Na Figura 7c, de modo semelhante às anteriores, a digestibilidade in vitro é afetada negativamente pelos teores de FB $(r=-0,94)$, FDN $(r=-0,97)$ e FDA $(r=-0,94)$. Estes dados comprovam que com o aumento do teor de fibras, o aproveitamento do alimento pelo animal diminui. 

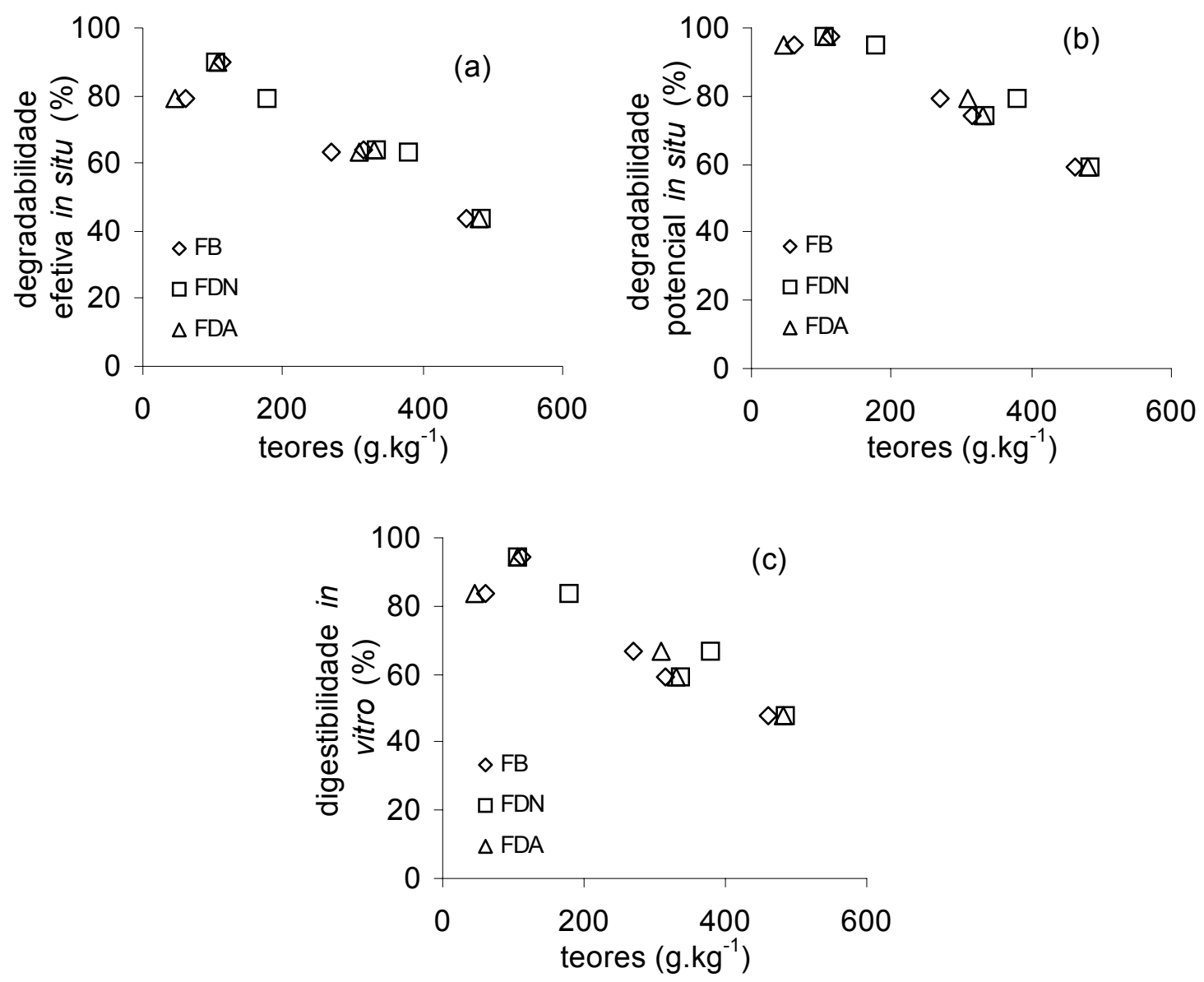

Figura 7. Correlações entre teores $\left(\mathrm{g} \cdot \mathrm{kg}^{-1}\right)$ em relação a degradabilidade efetiva (\%)(a), degradabilidade potencial in situ (\%)(b), digestibilidade in vitro $(\%)(c)$. Legenda: fibra bruta $(\diamond)$, fibra em detergente neutro ( $\square$ ) e fibra em detergente ácido $(\triangle)$.

Os resultados para degradabilidade mostraram uma alta correlação entre as metodologias testadas in vitro e in situ $(r=0,83 ; P<0,01)$, apresentando uma tendência linear positiva entre as metodologias utilizadas. Quando se compara as duas metodologias, observa-se que a técnica de produção de gases in vitro descreve melhor a cinética fermentativa dos substratos, principalmente no período inicial, denominado lag time, isso ocorre porque o modelo exponencial desenvolvido por Ørskov \& McDonald (1979) não consegue 
descrever a fase inicial do ataque microbiano (lag time), sendo um modelo apropriado para determinar valor nutritivo dos substratos (Figura 8).

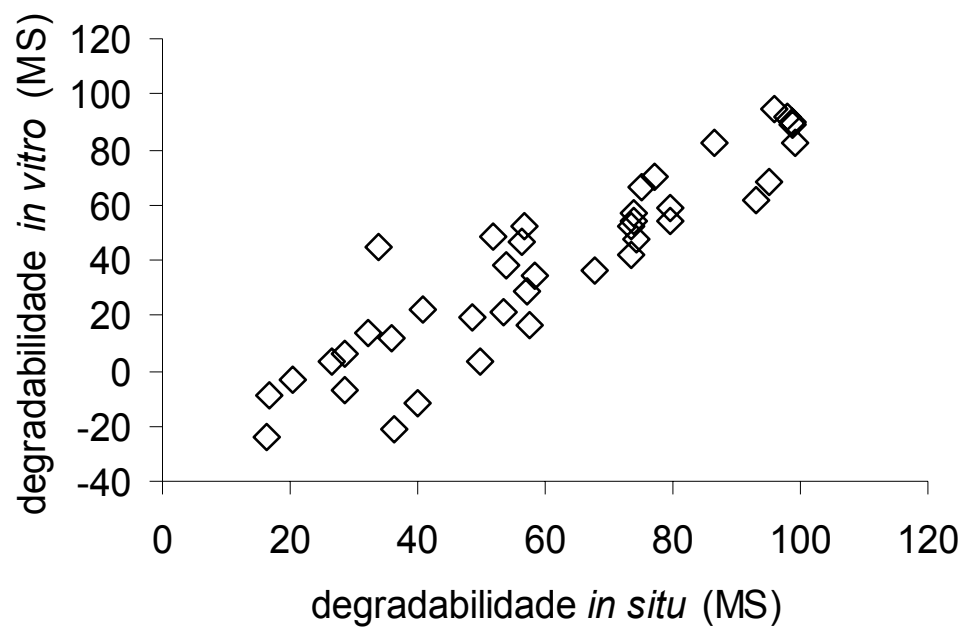

Figura 8. Comparação entre as degradabilidades da matéria seca (MS) determinadas por técnicas in vitro e in situ.

Os resultados apresentados na Figura 9 mostra uma forte correlação entre a técnica in situ e a técnica de Tilley \& Terry modificada ( $r=0,97 ; P<0,01)$, ocorrendo o mesmo quando correlacionada com a técnica in vitro de produção de gases $(r=0,97 ; P<0,01)$ num período de $48 \mathrm{~h}$. Essa alta correlação permite uma maior confiança nos resultados apresentados pela técnica in vitro de produção de gases e degradabilidade ruminal in situ, além de possibilitar que os resultados, quando se utiliza essas técnicas, possam ser correlacionados entre si. 

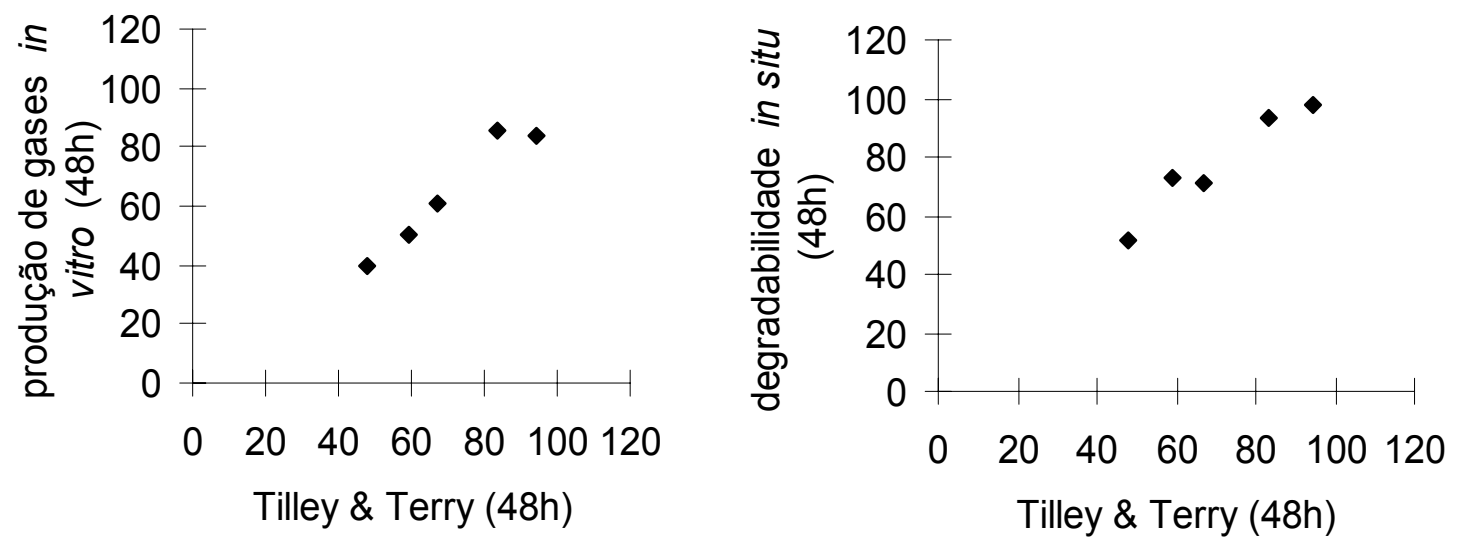

Figura 9. Correlações entre as técnicas in situ e in vitro da MS, determinadas pela técnica de Tilley \& Terry modificada. 


\section{CONCLUSÃO}

A técnica in vitro de incorporação de ${ }^{32} \mathrm{P}$ apresentou resultados satisfatórios em relação as variáveis testadas, portanto recomenda-se:

$\checkmark$ velocidade de centrifugação de $39.907 \mathrm{~g}$, para melhor manuseio das amostras;

$\checkmark$ a utilização de 4 lavagens para uma eficiência de descontaminação do radiofósforo extracelular e;

$\checkmark$ utilização apenas do líquido do conteúdo ruminal filtrado em gaze como fonte de inóculo;

Os resultados da técnica in vitro de produção de gases foram satisfatórios quando comparados com a literatura, portanto recomenda-se:

$\checkmark$ a utização do inóculo contendo $50 \%$ da fase líquida e $50 \%$ da fase sólida do conteúdo ruminal. 


\section{REFERÊNCIAS BIBLIOGRÁFICAS}

AGRICULTURAL AND FOOD RESEARCH COUNCIL - AFRC. Energy and protein requirement of ruminants. Wallingford: $C A B$ International, 1993. $159 p$.

ASSOCIATION OF OFFICIAL AGRICULTURAL CHEMISTS - AOAC. Official methods of analysis of the AOAC. 16.ed. Arlington: AOAC International, 1995. v.1, p.4/1-4/30.

BLÜMMEL, M.; MAKKAR, H.P.S.; BECKER, K. In vitro gas production: a technique revisited. Journal of Animal Physiology and Animal Nutrition, v.77, n.1, p.24-34, 1997a.

BLÜMMEL, M.; STEINGAB, H.; BECKER, K. The relationship between in vitro gas production, in vitro microbial biomass yield and $15 \mathrm{~N}$ incorporation and its implications for the prediction of voluntary feed intake of roughases. British Journal of Nutrition, v.77, p.911-921, 1997b.

BOER, G.; MURPHY, J.J. Mobile nylon bag for estimating availability of rumen undegradable protein. Journal of Dairy Science, v.70, n.5, p.977-982, 1987.

BRICARELLO, P.A.; LONGO, C.; GARCEZ, P.; BREMER NETO, H.; CABRAL FILHO, S.L.S.; BUENO, I.C.S.; ABDALLA, A.L. Comparações entre equações de predição de NDT e degradabilidade in vitro de alimentos para ruminantes (Compact disc). In: ENCONTRO CIENTíFICO DOS PÓS- 
GRADUANDOS NO CENA/USP, 6., Piracicaba, 2000. Resumos. Piracicaba: CENA/USP, 2000.

BUENO, I.C.S. Comparação entre técnica in vitro e in situ de avaliação de braquiária para ruminantes. Piracicaba, 1998. 133p. Dissertação (Mestrado) - Centro de Energia Nuclear na Agricultura, Universidade de São Paulo.

BUENO, I.C.S.; ABDALLA, A.L; CABRAL FILHO, S.L.S.; OWEN, E.; MOULD F.L.; MACHADO, M.C., GOBBO, S.P. Uso de líquido ruminal e fezes de bovinos e ovinos como fonte de inóculos para técnica in vitro de produção de gases (Compact disc). In: REUNIÃO ANUAL DA SOCIEDADE BRASILEIRA DE ZOOTECNIA, 36., Porto Alegre, 1999. Anais. Porto Alegre: SBZ, 1999.

BUENO, I.C.S.; GOBBO, S.P.; ABDALLA, A.L.; CABRAL FILHO, S.L.S. Effect of solid phase of rumen liquor on the inoculum used for in vitro gas production technique. In: SYMPOSIUM OF GAS PRODUCTION: FERMENTATIVE KINETICS FOR FEED EVALUATION AND ASSESS MICROBIAL ACTIVITY, Wageningen, 2000. Wageningen: BSAS, 2000. p.21-22.

BUENO, I.C.S.; CABRAL FILHO, S.L.S.; GOBBO, S.P.; MACHADO, M.C.; PAVAN, C.; ABDALLA, A.L. Effect of tropical diets on inocula used on in vitro gas production technique. In: ANNUAL MEETING OF THE BRITISH SOCIETY OF ANIMAL SCIENCE, York, 2001. Proceedings. Penicuik: BSAS, 2001. p.110.

CARVALHO, W.T. Efeito da alteração dos grãos de sorgo e milho pelo aquecimento, fermentação e moagem sobre a digestibilidade in vitro dos carboidratos e da matéria seca. Viçosa, 1980. 48p. Dissertação (Mestrado) - Universidade Federal de Viçosa. 
CHURCH, D.C.; PETERSEN, R.G. Effect of several variables on in vitro rumen fermentation. Journal of Dairy Science, v.43, n.1, p.81-82, 1960.

DOVE, H.; MILNE, J.A. Digesta flow and rumen microbial protein production in ewes grazing perennial ryegrass. Australian Journal of Agricultural Research, v.45, n.6, p.1229-1245, 1994.

EL-MEADAWAY, A.; MIR, P.S.; ZAMAN, M.S.; YANKE, L.J. Relative efficacy of inocula from rumen fluid or faecal solution for determining in vitro digestibility and gas production. Canadian Journal of Animal Science, v.78, n.4, p.673-679, 1998.

FISKE, C.H.; SUBBAROW, Y. The calorimetric determination of phosphorus. Journal of Biological Chemistry, v.66, p.1719-1725, 1925.

FRANCE, J.; DHANOA, M.S.; THEODOROU, M.K.; LISTER, S.J.; DAVIES, S.J.; ISAC, D. A model to interpret gas accumulation profiles with in vitro degradation of ruminant feeds. Journal of Theoretical Biology, v.163, p.99-111, 1993.

GOERING, N.K.; VAN SOEST, P. Forage fiber analysis: apparatus, reagents, procedures and some applications. Washington: USDA, 1970. 20p.

GRANT, R.J.; VAN SOEST, P.J.; McDOWELL, R.E. Influence of rumen fluid source and fermentation time on in vitro true dry matter digestibility. Journal of Dairy Science, v.57, n.2, p.1201-1205, 1974.

KEARL, L.C. Nutrient requirements in developing countries. Logan: International Feedstuff Institute. Utah State University, 1982.

LONGO, C.; BREMER NETO, H.; BRICARELLO, P.A.;GARCEZ, P.; CABRAL FILHO, S.L.S.; BUENO, I.C.S.; ABDALLA, A.L. Comparações entre equações de predição de NDT e degradabilidade in situ de alimentos para ruminantes (Compact disc). In: ENCONTRO CIENTíFICO DOS PÓSGRADUANDOS NO CENA/USP, 6., Piracicaba, 2000. Resumos. Piracicaba: CENA/USP, 2000. 
MAURICIO, R.M.; MOULD, F.L.; DHANOA, M.S.; OWEN, E.; CHANNA, K.S.; THEODOROU, M.K. Semi automation of the in vitro gas production technique using a pressure transducer. In: ANNUAL MEETING BRITISH SOCIETY OF ANIMAL SCIENCE, Scarborough, 1998. Posters. Scarboroug: BSAS, 1998. p.70.

MAURICIO, R.M.; MOULD, F.L.; DHANOA, M.S.; OWEN, E.; CHANNA, K.S.; THEODOROU, M.K. Semi automated in vitro gas production technique for ruminant feedstuff evaluation. Animal Feed Science and Technology, v.79, p.321-330, 1999.

MAYNARD, L.A.; LOOSLI, J.K.; HINTZ, H.F.; WARNER, R.G. Nutrição animal. 3.ed. Rio de Janeiro: Livraria Freitas Bastos, 1984. 726p.

MCDONALD, I. A revised model for the estimation of protein degradability in the rumen. Journal of Agricultural Science, v.96, p.251-252, 1981.

MEHREZ, A.Z.; ØRSKOV, E.R. A study of the artificial fibre bag technique for determining the digestibility of feeds in the rumen. Journal of Agricultural Science, v.88, n.3, p.645-650, 1997.

NATIONAL RESEARCH COUNCIL - NRC. Nutrient requirements of dairy cattle. 7.ed.rev. Washington: National Academy Press, 2001. 381p.

NOCEK, J.E. Evaluation of specific variables affecting in situ estimate of ruminal dry matter and protein digestion. Journal of Animal Science, v.60, n.5, p.1347-1358, 1985.

ØRSKOV, E.R.; McDONALD, I. The estimation of protein degradability in the rumen from incubation measurements weighted according to rate of passage. Journal of American Science, v.92, p.449-453, 1979.

ROCHA, G.P. Efeito da idade na composição química, digestibilidade in vitro e taxa de fermentação de oito gramíneas tropicais. Lavras, 1979. 104p. Dissertação (Mestrado) - Escola Superior de Agricultura. 
SAS INSTITUTE. The SAS system for windows. Release 8.01. Cary, 2000.

SOBRINHO, L.I. Efeito da alteração dos grãos de sorgo e de milho pelo aquecimento, fermentação e moagem sobre a digestibilidade in vitro da proteína e da matéria seca. Viçosa, 1980. 50p. Dissertação (Mestrado) Universidade Federal de Viçosa.

TAMMINGA, S.; WILLIAMS, B.A. In vitro techniques as tools to predict nutrient supply in ruminants. In: DEAVILLE, E.R.; OWEN, E.; ADESOGAN, A.T.; RYMER, C.; HUNTINGTON, J.A.; LAWRENCE, T.L.J. (Ed.) In vitro techniques for measuring nutrient supply to ruminants. Edinburgh: BSAS, 1998. p.1-11. (BSAS Occasional Publication, 22).

THEODOROU, M.K.; WILLIANS, B.A.; DHANOA, M.S.; MCALLAN, A.B.;

FRANCE, J. A simple gas production method using a pressure transducer to determine the fermentation kinetics of ruminant feeds. Animal Feed Science and Technology, v.48, p.185-197, 1994.

TILLEY, W.H.; TERRY, R.A. A two stage technique for in vitro digestion of forage crops. Journal of the British Grassland Society, v.8, n.1, p.104111, 1963.

VAN NEVEL, C.; DEMEYER, D.I. Determination of rumen microbial growth in vitro from 32-P labelled phosphate incorporation. British Journal of Nutrition, v.38, p.101-114, 1977.

VAN SOEST, P.J.; WINE, R.H. Use of detergent in the analysis of farmersfeeds. IV. Determination of plant cell wall constituents. Journal of Association of Analytical Chemistry, v.50, p.50-55, 1967.

VAN SOEST, P.J.; ROBERTSON, J.B.; LEWIS, B.A. Methods for dietary fiber, neutral detergent fiber and nonstarch polysaccharides in relation to animal nutrition. Journal of Dairy Science, , v.74, n.10, p.3583-3597, 1991. 
VITTI, D.M.S.S.; SILVA FILHO, J.C. Comparison of energy sources for rumen microorganisms using ${ }^{32} \mathrm{P}$ incorporation. Journal of Nuclear Agriculture and Biology. v.14, p.85-86, 1985.

VITTI, D.M.S.S.; SILVA FILHO, J.C.; ABDALLA, A.L. Phosphorus availability for rumen microorganisms: effect of different sources. Journal of Nuclear Agriculture and Biology, v.7, p.186-187, 1988.

WEBER, O.L. Crescimento, coeficiente de digestibilidade da matéria seca, concentração e extração de nutrientes pelo Panicum maximum Jacq. Cv. Makveni dos 30 aos 180 dias de idade. Piracicaba 1984. 77p. Dissertação (Mestrado) - Escola Superior de Agricultura "Luiz de Queiroz", Universidade de São Paulo.

WEISS, W. P. Estimation of digestibility by laboratory methods. In: G.C. FAHEY Jr, L.E. MOSER, D.R. MERTENS, M. COLLINS. NATIONAL CONFERENCE ON FORAGE QUALITY, EVALUATION AND UTILIZATION, Lincoln, 1994. Lincoln, 1994. p.644-681. 